\title{
UNGÜENTARIOS BIZANTINOS CON SELLO EPIGRÁFICO EN CARTHAGO SPARTARIA
}

\author{
POR \\ JAIME VIZCAÍNO SÁNCHEZ \\ Universidad de Murcia - Fundación Cajamurcia \\ INMACULADA PÉREZ MARTÍN \\ Investigadora científica del ILC, CCHS, CSIC
}

\section{RESUMEN}

Este artículo presenta una serie de late Roman unguentaria de los siglos VI-VII d.C, hallados en las recientes excavaciones llevadas a cabo en Carthago Spartaria, la actual Cartagena, en España. Estos ungüentarios son analizados en función de su tipología, cronología, contexto, función, sellos y patrones de distribución e incrementan la nómina de evidencias arqueológicas sobre la presencia bizantina en Spania, proporcionándonos nuevos datos acerca de la arqueología, la historia y la economía de este territorio durante este período.

\section{SUMMARY}

This article presents a large group of sixth-seventh Century late Roman unguentaria retrieved in the recent excavations at Carthago Spartaria, modern Cartagena, Spain. These unguentaria are studied in their typology, chronology, context, function, stamps and distribution patterns; they increase the body of archaeological evidence about Byzantine presence in Spania, providing us with new information about the archaeology, history and economy of this territory during this period.

PALABRAS CLAVE: Late Roman Unguentaria. Presencia bizantina en Spania. Siglos VI-VII d.C.

KEY WORDS: Late Roman Unguentaria. Byzantine presence in Spania. Sixth-Seventh Century AD.

\section{INTRODUCCIÓN ${ }^{1}$}

Las excavaciones arqueológicas que en el curso de las dos últimas décadas han venido realizándose en la ciudad de Cartagena, han supuesto un avance considerable en el conocimiento de la etapa tardía que vive ésta, momento en el que, tras haber sido promocionada en época dioclecianea como capital de la provincia Carthaginensis, se convierte en uno de los principales centros direccionales de la presencia bizantina en España ${ }^{2}$.

\footnotetext{
${ }^{1}$ Queremos agradecer a la Dra. Elena Ruiz Valderas, Directora del Museo del Teatro Romano de Cartagena, las facilidades dadas para el estudio de las piezas que presentamos en este estudio, así como a Dña. Soledad Pérez-Cuadrado el
}

Bien en virtud de la presencia de un contingente militar que exige la imbricación de la ciudad en las redes de distribución de la restaurada annona, bien en virtud de la actuación de los negotiatores Graeci o $\sigma \pi \alpha v o \delta \rho o ́ u o \iota$ asentados previamente en el solar hispano, o quizá mejor, en virtud de la confluencia de ambas iniciativas, estatal y privada, la ciudad aparece volcada al mercado mediterráneo, descansando su abastecimiento en una dinámica importación ${ }^{3}$. Dentro de este comercio, si bien es cierto que el África bizantina acapara el protagonismo, también hay una fuerte presencia oriental, que explica la presencia de materiales como los que nos disponemos a analizar, los ungüentarios orientales tradicionalmente englobados bajo la genérica denominación de late Roman unguentaria y en la actualidad mucho mejor conocidos gracias a nuevos análisis tipológicos y de pastas $^{4}$. La masiva llegada de éstos exige detenerse en su análisis y contextualización, a fin de explicarnos su presencia en la Península e interpretar su función.

\section{CARTHAGO SPARTARIA EN ÉPOCA BIZANTINA}

La presencia bizantina en Cartagena supone un jalón más en la cadena de transformaciones que su

dibujo de la mayor parte de las mismas. Igualmente, estamos en deuda con el Dr. Luis Caballero Zoreda por la lectura de este manuscrito y amables sugerencias para su mejora.

${ }^{2}$ Acerca de la secuencia de acontecimientos, cf. Vallejo (1993). Para la ciudad debemos destacar la actuación del magister militum Comitiolus, quien interviene en sus murallas. Cf. a este respecto, Fontaine (2000) y, acerca del nombre del magister militum, cf. Prego de Lis (1999) y (2000).

${ }^{3}$ La Lex Visigothorum dedica un título a estos comerciantes orientales, De transmarinis negotiatoribus (LV, XI, III). Cf. a este respecto, Marlasca (2001).

${ }^{4}$ Hayes (1971). 


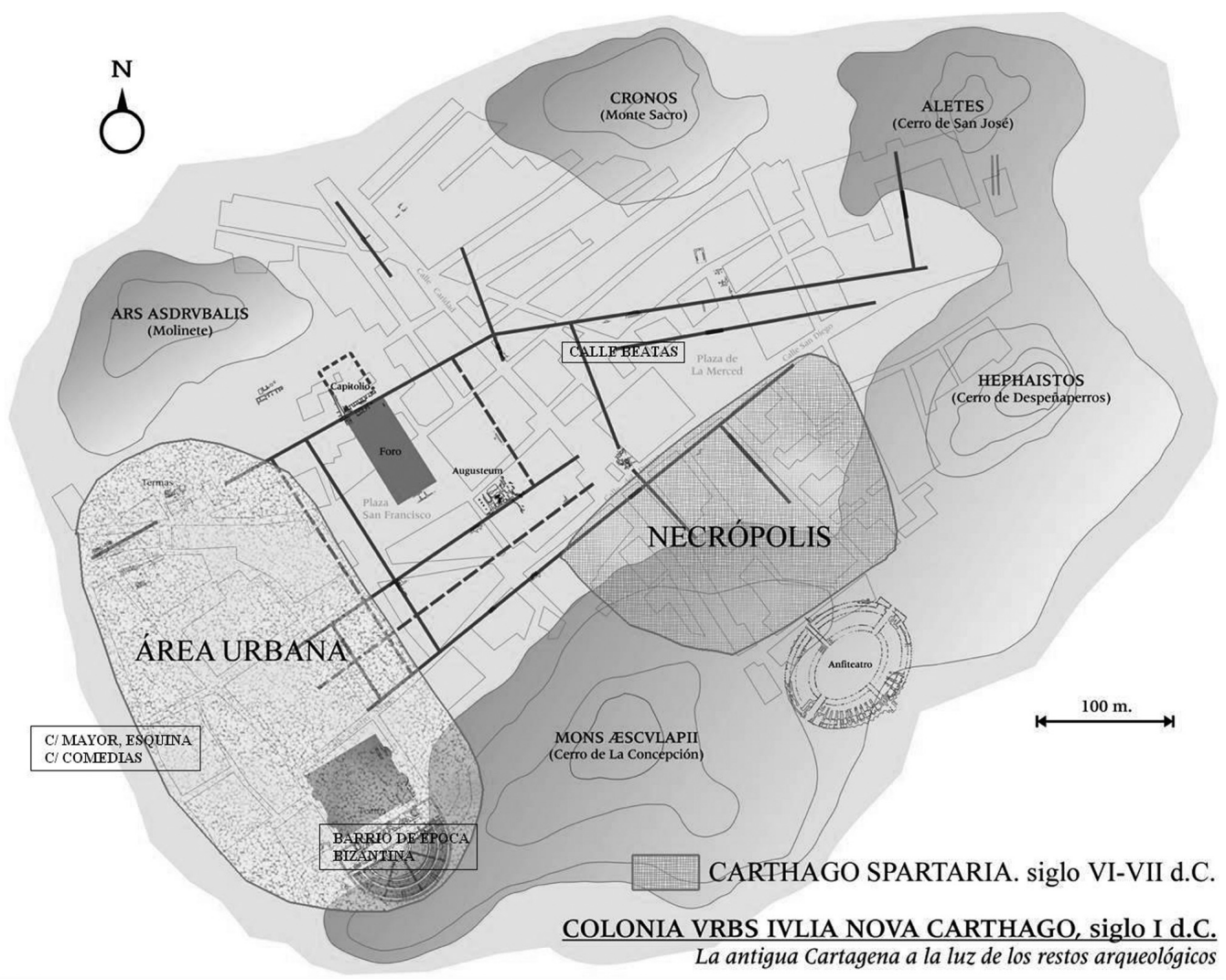

Fig. 1. Cartago Spartaria en época bizantina. Se señalan los puntos donde han aparecido los ungüentarios analizados en el texto.

fisonomía urbana experimenta al menos ya desde el siglo II d.C., marcando el tránsito entre la antigua civitas y la madina islámica (Fig. 1$)^{5}$.

Para la etapa conocemos un extenso barrio levantado sobre el antiguo teatro romano que, al igual que otros instalados en este tipo de edificios de espectáculos, presenta sus viviendas reocupando los antiguos espacios y, de forma especial, aterrazadas sobre el antiguo graderío (Fig. 2).

A pesar del aspecto humilde del conjunto, los contextos materiales muestran un poder adquisitivo no despreciable, en donde el abastecimiento de productos como el aceite, vino o salazones depende de mercados externos, muy especialmente del norte de África, de donde, junto a la vajilla de mesa, compuesta por los tipos más tardíos de terra sigillata Africana D, se importan las ánforas Keay XXXII, LXI, LXII o numerosos spatheia, complementados, en menor medida, por los envases orientales LRA1/Keay LIII; LRA 2/Keay LXV o LRA4/Keay LIV, en cuyos fletes

\footnotetext{
${ }^{5}$ Ramallo y Vizcaíno (2003) y Vizcaíno [en prensa].
}

debieron incluirse los ungüentarios objeto de estudio de este trabajo ${ }^{6}$.

Se integra también en el ajuar doméstico la vajilla vítrea, con un repertorio vascular donde cuencos tipo Isings 116 y frascos de morfología diversa - muy especialmente las copas tipo Isings $111-$, constituyen las formas más recurrentes ${ }^{7}$, aunque tampoco faltan envases singulares, como un cuerno de vidrio para beber.

La situación de este barrio encaramado al cerro de la Concepción, que custodia la zona portuaria y en torno al cual, al igual que ocurre hasta época moderna, debió de gravitar la defensa de la ciudad - lo que explicaría la posible existencia de un castellum que precedería la fortificación medieval hoy conservada-, parece sugerir su vinculación a la guarnición bizantina que el kastron acogería y a cuyo mantenimiento se destinarían las mercancías importadas a veces, de hecho, en un número que deja ver

\footnotetext{
${ }^{6}$ Ramallo, Ruiz y Berrocal (1996), pp. 143-146.

${ }^{7}$ Sánchez de Prado (1999).

${ }^{8}$ Vizcaíno (2005).
} 


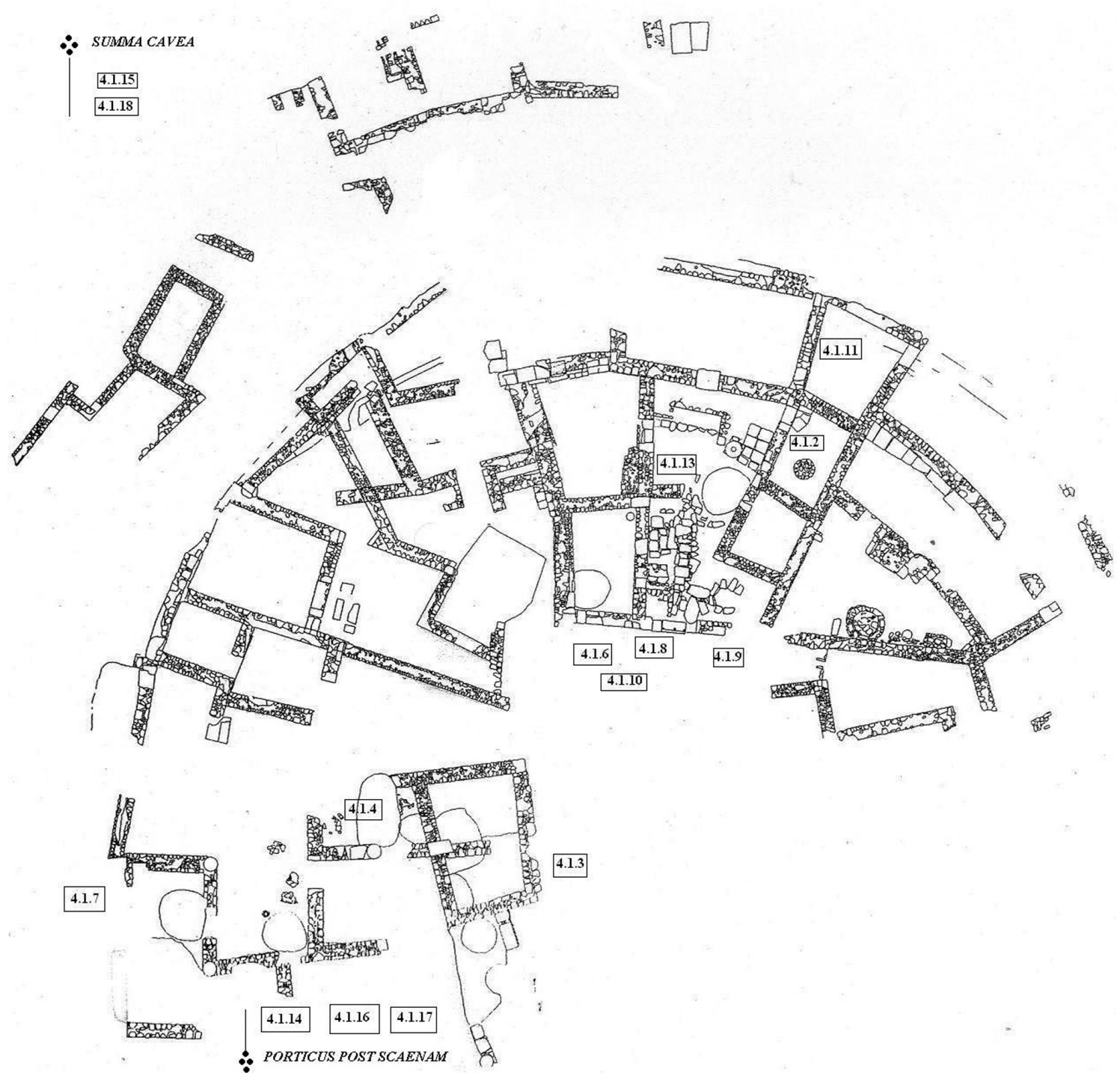

Fig. 2. Barrio de época bizantina levantado sobre el teatro romano de Cartagena (Archivo de la Fundación Teatro Romano de Cartagena). Se indica el lugar donde han aparecido los ungüentarios.

un carácter de almacenamiento que excede las necesidades domésticas ${ }^{9}$. Induce a pensar lo mismo la documentación en algunas de las estancias del barrio de elementos pertenecientes al equipamiento militar protobizantino, sea el caso de puntas de flecha de tipo ávaro, sea, muy especialmente, el de una coraza laminar, con paralelos en otros lugares mediterráneos ${ }^{10}$.

Nuestro conocimiento de la ciudad durante este período también ha avanzado gracias al descubrimiento de un espacio cementerial que, vigente hasta el

\footnotetext{
${ }^{9}$ Ramallo y Vizcaíno (2007).

${ }^{10}$ Vizcaíno (2007) y (2007bis).
}

primer cuarto del siglo vII d.C., se encuentra ya en uso desde el siglo v d.C. ${ }^{11}$.

En conjunto, aun cuando la documentación arqueológica de Cartagena sea todavía parca para los dos principales vectores de la transformación urbana durante la etapa bizantina - la fortificación del recinto urbano y la cristianización de su topografía-, la evi-

\footnotetext{
${ }^{11}$ Madrid y J. Vizcaíno (2006). Acerca de sus ajuares, que se han dividido en dos categorías: el de tipo simbólico, compuesto por jarras y ungüentarios, y el denominado personal, que engloba elementos de indumentaria y adorno corporal, cf. Vizcaíno y Madrid (2006) y Madrid y Vizcaíno (2006bis), (2007) y (2008).
} 
dencia arqueológica hoy disponible hace de la ciudad una pieza clave para la comprensión de la presencia de los milites Romani en Spania ${ }^{12}$.

\section{LOS UNGÜENTARIOS TARDÍOS DE ORI- GEN ORIENTAL. TIPOLOGÍA, DATACIÓN Y DISTRIBUCIÓN}

Hasta ahora, dentro de la denominación de late Roman unguentaria, se han recogido distintas producciones datadas entre los siglos v y vII d.C. que, a pesar de contar con características comunes como su morfología ahusada y su procedencia oriental, resultan ciertamente diversas. Es por ello por lo que, de cara a una más correcta individualización, se ha señalado la existencia de tres tipos distintos, para los que se propone una diversa denominación ${ }^{13}$. Así, para la variante tradicional ${ }^{14}$, se sugiere emplear el término early Byzantine ampulla, mientras que para otra caracterizada por su pasta altamente micácea, la hasta ahora denominada late Roman unguentarium type $B^{15}$, se propone Ephesian early Byzantine ampulla. Finalmente, una tercera variante, la llamada Unguentarium $M 369^{16}$, petrográficamente tiene también su origen localizado en Éfeso, razón por la que se apuesta por clasificarla como Ephesian early Byzantine amphoriskos, a pesar de no tener asas ${ }^{17}$.

Desgraciadamente, no siempre es fácil la diferenciación entre estas variantes, en especial cuando no se ha tenido ocasión de trabajar directamente con las piezas y se intenta realizar la discriminación únicamente a través de la documentación gráfica o textual existente. Tengamos en cuenta a este respecto que claras diferencias morfológicas únicamente se dan entre las dos primeras y la última, en tanto que, para diferenciar aquéllas entre sí, la morfología ayuda sólo en puntuales ocasiones, residiendo el principal criterio diferenciador en la composición de la pasta, altamente micácea en el caso de la Ephesian early Byzantine ampulla y sólo esporádica en el caso de la otra. De la misma forma, si bien los sellos son característicos de esta última, tampoco se limitan a ella, sino que ocasionalmente aparecen también en los ungüentarios de origen efesio.

Poco a poco, se va perfilando un mapa de distribución de las piezas cada vez más completo, de tal

\footnotetext{
12 Ramallo y Vizcaíno (2002).

${ }^{13}$ Lochner et al. (2005).

14 Hayes (1971).

15 Riley (1975), p. 37.

${ }^{16}$ Robinson (1959), p. 118 y P1. 34

${ }^{17}$ Lochner et al. (2005), pp. 650-651.
}

forma que si, inicialmente, cuando J.W. Hayes individualizó el tipo, su documentación era reducida, los estudios posteriores confirman una difusión capilar por prácticamente todo el Mediterráneo ${ }^{18}$. Precisamente, de dichos mapas, siempre y cuando no nos encontremos ante un déficit de investigación en algunas áreas, parecen desprenderse importantes datos para una de las principales incógnitas que suscitan estos ungüentarios, la de su procedencia. En este sentido, cabe notar que, o están ausentes o su presencia es poco significativa en los Balcanes, donde faltan incluso en alguno de los centros más dinámicos como Salónica, así como también en Egipto, pero sobre todo en Siria, hecho que viene a cuestionar seriamente la tradicional localización de su foco productor en la región palestina ${ }^{19}$. En función de los datos actualmente disponibles, este tipo de ungüentarios parece estar mejor representado en las zonas donde el poder bizantino tuvo continuidad, como Atenas, Corinto, Asia menor occidental (incluida Rodas y Samos) y Cilicia. De hecho, es en Asia Menor donde se da la mayor concentración y el propio J.W. Hayes, en el congreso celebrado en Roma en 1995, aceptaba una nueva localización en Panfilia de la producción de $\mathrm{LRU}^{20}$.

De forma coherente, aunque los componentes mineralógicos de más amplia difusión dificultan circunscribir el área de producción, se ha destacado la presencia de serpentina, característica de las producciones salidas de los talleres de Asia Menor suroccidental, Cilicia, Norte de Siria o Chipre, siendo quizás entre todas Cilicia, región muy activa en el panorama productivo y comercial de época protobizantina, y además, al igual que la región suroccidental de Asia Menor, frecuente área de peregrinación, el más probable centro productor de este tipo de enva$\operatorname{ses}^{21}$. No obstante, algunos autores, en la línea inicial de Hayes, siguen insistiendo en un origen en Palestina, como sucede con los que señalan la existencia de cerámicas con pastas parecidas en la región de Betania $^{22}$. De hecho, hay que reconocer que, a pesar de la presencia de inclusiones mínimas, apenas distinguibles, la técnica de elaboración, que conlleva el aplique de engobe por inmersión y una cocción prolongada a altas temperaturas, en principio no encuentra paralelos en las coetáneas producciones

\footnotetext{
${ }^{18}$ Reynolds (1993), fig. 121; Baldoni (1999), fig. 2; Metaxas (2005), p. 77, Abb. 7.

${ }^{19}$ Hayes (2001) no menciona los LRU en este estudio sobre la presencia de cerámicas mediterráneas («internacionales») en Siria-Jordania.

${ }^{20}$ Así lo menciona Saguì (1998), p. 311.

${ }^{21}$ Lochner et al. (2005), p. 648.

${ }^{22}$ Uscatescu (1996), p. 89.
} 


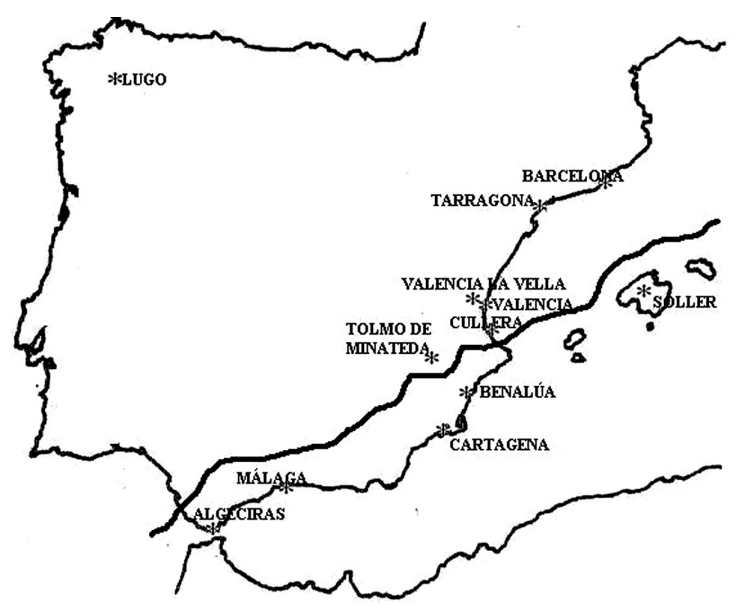

Fig. 3. Yacimientos españoles donde han aparecido ungüentarios. Se indica el límite hipotético de la Spania bizantina.

microasiáticas y sí por el contrario en clases cerámicas palestinas y jordanas, explicándose quizás así el elevado número de piezas que están deparando los yacimientos de Asia Menor únicamente en la atención que de un tiempo a esta parte están recibiendo y no necesariamente, por tanto, en que sean la zona de producción ${ }^{23}$. De esta forma, en lo referente al área de procedencia, se trata de una cuestión aún no cerrada del todo.

En el caso de los ejemplares documentados en España, hasta ahora no se ha incidido en la diferenciación de variantes que se propone en la actualidad, manteniéndose la denominación genérica tradicional. En cualquier caso, la nómina de piezas se ha incrementado de forma sustancial en los últimos años, hasta el punto de que si hasta hace poco apenas se conocían más que las halladas en Cartagena ${ }^{24}$ y en el yacimiento valenciano de la Punta de l'Illa de Cullera, hoy en día el mapa de distribución incluye otra serie de puntos (Fig. 3) ${ }^{25}$. A este respecto, las piezas publicadas se dan sobre todo en núcleos que, al igual que Cartagena, pertenecen a la Spania imperial, como Málaga ${ }^{26}$, Algeciras ${ }^{27}$, Benalúa (Alican-

\footnotetext{
${ }^{23}$ Baldoni (1999), p.132.

${ }^{24}$ Berrocal (1997).

${ }^{25}$ García y Rosselló (1993).

${ }^{26}$ Se siguen documentando piezas en intervenciones recientes, como la practicada en $\mathrm{C} /$ Císter, aún inédita, pero el hallazgo más interesante, en número y estado de conservación, es el llevado a cabo en el Palacio del Obispo, donde, en el nivel de amortización de la muralla romana, se recuperó un lote de diez ejemplares, todos sin sello, que se han ido publicando en distintas sedes (TIA [2000], p. 274, lám. 7, y Acién et al. (2003), p. 414, fig. 3. 29-30), recogiéndose, en cualquier caso, de forma íntegra en TIA (2001). Queremos agradecer al arquéologo Ildefonso Navarro Luengo, Director
}

te ${ }^{28}$ o el valle mallorquín de Sóller $^{29}$, pero también en otra serie de yacimientos que, como ocurre en el caso de Punta de l'Illa de Cullera, se mueven en el área de influencia de la provincia bizantina y que, en algún caso y sólo de forma puntual, efímera, pudieron llegar a estar también incluidos en ésta, como el Tolmo de Minateda, València la Vella (Riba-roja de Tùria, Valencia) o la misma Valencia ${ }^{30}$. Parece, por el contrario, que su presencia en áreas más alejadas de esta zona es extraña, si bien no faltan ejemplares en ambos extremos septentrionales de la Península, tanto en la fachada mediterránea, donde conocemos sendas piezas de Tarragona y Barcelona ${ }^{31}$, respecti-

del área de Patrimonio Histórico del Ayuntamiento de Estepona, y miembro del equipo de excavación en algunas de las intervenciones llevadas a cabo en la capital malacitana, sus amables informaciones acerca de este tipo de materiales en la ciudad.

${ }^{27}$ Aquí conocemos dos de estas piezas, una de ellas hallada prácticamente completa en el solar de la calle San Nicolás 1 (Navarro et al. [2000], p. 226, lám. 3) y otra, también en muy buenas condiciones de conservación y con un interesante sello zoomorfo, recuperada en la calle Méndez Núñez n. ${ }^{\circ} 4$; cf. D. Bernal (2003), p. 34.

${ }^{28}$ Reynolds (1993), p. 144 y más recientemente, Reynolds (2003), fig. 5.7.

${ }^{29}$ De aquí se cita una pieza dudosa, documentada en Castelló, Can Bleda, Sóller, donde también se pudieron recoger materiales acordes a esta cronología, como los tipos Hayes 103, 104 o 107 en terra sigillata Africana D. Cf. Coll (1997), lám. II.134. Con todo, las síntesis realizadas sobre el panorama cerámico de la isla no mencionan más este tipo de materiales. Cf. así Gumà et al. (1997). A este respecto, queremos agradecer a M. A. Cau Ontiveros, investigador del Equip de Recerca Arqueomètrica de la Universitat de Barcelona (ERAUB), la información acerca de estas piezas en las islas, compartiendo con nosotros la opinión de que, a pesar de disponerse de tan sólo un ejemplar publicado, éstas no debieron de faltar.

${ }^{30}$ Queremos agradecer al arqueólogo M. Rosselló Mesquida la información acerca de la existencia de abundantes fragmentos de estas piezas en València la Vella, que desconocíamos, informándonos también de que, al igual que las de l'Almoina, además de no estar selladas, pertenecen a la misma fábrica que los ejemplares de Cullera, o lo que es lo mismo, a la variante tradicional de ungüentarios, que estudiaremos como Early Byzantine ampulla. Dicha existencia se daba ya a conocer en Pascual et al. (1997), p. 183. Cf. ahora nuevamente, Roselló (2005), fig. 11. Respecto a las piezas del Tolmo y Valencia, Gutiérrez et al. (2003), p. 138, fig. 22.6, y Roselló et al. (2003), p. 92.

${ }^{31}$ El ejemplar tarraconense, depositado en el Museu Nacional Arqueològic de Tarragona (n. ${ }^{\circ}$ inv. 12025), procede de un lote cerámico recogido en las excavaciones dirigidas por Serra Vilaró durante 1928-1929 en la necrópolis paleocristiana de la ciudad, concretamente en el sector comprendido entre la alcantarilla y el muro de cierre septentrional de la Fábrica de Tabacos. Presentado inicialmente por Serra (1929), p. 89, lám. LXXI,13, su correcta clasificación se ha llevado en tiempos recientes (Remolà [2000], p. 101, n. 179), habiéndole sido dedicado un pequeño estudio (Bádenas de la Peña [2003], n. ${ }^{\circ} 87$, p. 146). Agradecemos a J. A. Remolà Vallverdú, Conservador de Documentació i Recerca del MNAT, la información dada para el estudio de esta pieza. Por otro lado, los ungüentarios que analizamos se documentan también en 
vamente, como en la zona gallega, en donde, recientemente, se ha hallado una pieza en Lugo. En cambio, por ahora, no se conoce su existencia, por cuanto nos consta, en otros puntos del territorio visigodo, ni siquiera al parecer en Mérida, ciudad especialmente volcada al mundo oriental, como deja ver otro tipo de evidencias y en la que no habría que descartar por ello mismo su documentación ${ }^{32}$.

Así las cosas, se dibuja un mapa de distribución que esencialmente se ciñe al ámbito de soberanía e influencia bizantina y que en el caso de los puntos más excéntricos del tipo de Tarragona o Barcelona, dado que últimamente también se han hallado piezas de este tipo en Marsella o Luni, se explicarían en su calidad de área bisagra entre la Spania y la Italia imperiales $^{33}$. De la misma forma, también podemos ver que dicho mapa de distribución es sobre todo costero, con mínimas excepciones, y en general, poco alejadas de la costa, como ocurre con el Tolmo de Minateda o València la Vella (Riba-roja de Tùria, Valencia). Por lo demás, la presencia es desigual en estos puntos, de tal forma que, como cabe esperar en este contexto, dada su importancia y mayor demanda, las concentraciones más significativas se dan en dos de los principales centros de la Spania bizantina: Málaga y, sobre todo, Cartagena, que dispone casi de un centenar ${ }^{34}$. Sorprende, sin embargo, teniendo en cuenta estas pautas, que otro importante núcleo de la Spania bizantina, Septem, no reciba, al parecer, este tipo de ungüentarios, algo que consideramos tan sólo un problema de registro, habida cuenta que sí se dan, y hasta con cierta frecuencia, en el ámbito geográfico del norte de África, en lugares como Berenice, Apolonia, Ptolemais, Tocra, Cirene, Sabratha, Hadrianópolis, Alejandría o Cartago ${ }^{35}$. En el mismo senti-

Barcino, donde podemos citar al menos uno de ellos, conservada en su integridad, procedente del complejo episcopal de Plaza del Rei (Beltrán de Heredia [2001], n. o 295). Agradecemos a J. Beltrán de Heredia, Conservadora en Cap del Conjunt Monumental Plaça del Rei-Museu d'Historia de la Ciutat, su amabilidad para el estudio de esta pieza, cuya existencia desconocíamos.

${ }^{32}$ Hemos consultado con el arqueólogo M. Alba Calzado, del Consorcio Monumental de Mérida, a quien hemos de agradecer su gentil respuesta, la presencia de este tipo de piezas en Mérida y su entorno lusitano, confirmándonos que, por ahora, no hay constancia de su aparición.

${ }^{33}$ En dicha situación se ha fundamentado así la diversidad de los contextos materiales del Mediodía francés y arco ligur, como señala Murialdo (2001).

${ }^{34}$ Berrocal (1997) y Ramallo et al. (1997), pp. 210-211. De hecho, también la revisión de los materiales de algunas excavaciones de la ciudad nos ha permitido documentar nuevos ejemplares, sea el caso de los presentes en los vertederos tardoantiguos como el de calle Cuatro Santos, n. ${ }^{\circ}$ 17. Acerca de estos contextos, cf. J. Vizcaíno (1999).

${ }^{35}$ Lochner et al. (2005), p. 649; Reynolds (1993), p. 144 , y Riley (1979), p. 363. do, tampoco en el otro gran baluarte de la presencia bizantina en el marco hispano, las Baleares, dicho recipiente parece ser significativo, de tal forma que apenas tenemos constancia más que de algún ejemplar, caso del dudoso recuperado en el mallorquín Valle de Sóller. No obstante, de la misma forma que la distribución de los ungüentarios orientales por el territorio norteafricano hace verosímil su presencia en Septem, también el hecho de que éstos se registren en toda la zona alrededor de las Baleares, desde la misma África septentrional por el sur, las costas francesa e italiana por el norte (Marsella o Luni ${ }^{36}$ ) y la italiana (Roma, Siracusa o Cerdeña ${ }^{37}$ ) y española (sureste y levante), a oeste y este, respectivamente, sugiere que también debieron de hacerlo aquí y además de forma destacada, dado el papel que las islas desempeñan en los contactos mediterráneos.

Respecto a la cronología, también últimamente se va perfilando un panorama mucho más complejo del inicialmente establecido, de tal forma que, si en un principio se pensó circunscrita a los siglos VI-VII d.C, sin duda alguna el período de circulación más intenso, hoy en día parece extenderse tanto en su límite inferior como en el superior, cuestión especialmente interesante para el marco hispano, pues, a pesar de la evidente filiación oriental de los ungüentarios, se hace patente que no necesariamente hubieron de comercializarse durante el período de dominación bizantina en el mediodía peninsular. Así, por cuanto se refiere al inicio de su producción, lo cierto es que parece arrancar ya del siglo v d.C, como demuestran los ejemplares recuperados en la basílica del lado norte del ágora civil de Éfeso ${ }^{38}$. En lo relativo a su cese, habría que datarlo incluso a principios del siglo vIII d.C, pues, si ya su presencia en depósitos del siglo vII avanzado como la Crypta Balbi en Roma era garante de una circulación activa aún en ese período, la constatación de ejemplares en niveles posteriores, como es el caso de los recuperados en Iasos, confirma una perduración bastante tardía ${ }^{39}$. En este sentido, de confirmarse esta data avanzada, lo cierto es que también podría utilizarse como argumento en la polémica acerca de la procedencia de este tipo

\footnotetext{
${ }^{36}$ La presencia en las ciudades francesa e italiana queda recogida respectivamente por Clarc y D’Agnel (1904), p. 82, VIII, 1, y Lusuardi y Murialdo (1991), tav. 1, nn. 1-3, señalando su aparición en contextos de los siglos VI-VII d.C.

${ }^{37}$ En el caso de Roma, se trata de ejemplares recogidos tanto en el Foro Romano (Paganelli [2001], p. 193, I.4.72), como en Crypta Balbi (Saguì [1998], p. 311, fig. 4.6). Por cuanto se refiere a Siracusa, cf. Hayes (1971), p. 248, y Baldoni y Franco (1995), n. 7. En referencia a Cerdeña, se conoce un fragmento inédito, citado ibidem, n. 11.

${ }^{38}$ Mitsopoulos-Leon (1991), p. 150, Taf. 220.

${ }^{39}$ Baldoni y Franco (1995), p. 124.
} 
de recipientes, ya que la tradicionalmente señalada, Tierra Santa, chocaría con el obstáculo de encontrarse en dicho momento en manos árabes, situación que abriría un abanico de posibilidades: el definitivo descarte de esta procedencia, como parecen apuntar los análisis mineralógicos referidos; la existencia de otro territorio productor que continuara el suministro en Anatolia occidental ${ }^{40}$, suspendido el de esta área; o simplemente, una continuidad de la producción bajo los nuevos dominadores, como parece ocurrir con otros productos ${ }^{41}$.

Dentro de esta problemática cronológica, los ejemplares hispanos también pueden aportar algo, pues, aunque no hay constancia del contexto de todos, como ocurre con el caso de las piezas de València la Vella, recogidas en prospecciones superficiales, en otros casos es posible establecer unos márgenes cronológicos concretos. A este respecto, si bien en algunos casos sólo hay certidumbre de un contexto genéricamente tardío, como ocurre con la pieza tarraconense, hallada en la necrópolis paleocristiana de la ciudad, prácticamente todos los ungüentarios se datan en el período de circulación más intenso, es decir, a partir de época justinianea y, al parecer, no más allá del primer cuarto del siglo vII d.C.

En relación a la datación, también se han intentado establecer algunas seriaciones y así la presencia o no de sello se ha considerado indicio cronológico, por más que, sin embargo, no haya total consenso, de tal forma que, mientras que la mayoría de autores consideran que los ejemplares sellados son los más antiguos, desapareciendo en el siglo vII d.C. . $^{42}$ otros, en cambio, parecen sostener lo contrario ${ }^{43}$.

Sea como fuere, también para esta cuestión las piezas de Cartagena permiten un estudio más atento.

\section{UNGÜENTARIOS TARDÍOS DE ORIGEN ORIENTAL EN CARTAGENA}

Si ya las excavaciones efectuadas en la ciudad desde finales de los años sesenta habían proporcionado abundantes ungüentarios, la intensificación de las intervenciones a partir de la década de los noventa

\footnotetext{
${ }^{40}$ Cottica (1998) y (2000); Sauer y Ladstätter (2005).

${ }^{41}$ A este respecto, Hayes (1971), p. 245, señalaba el cese de la comercialización circa 650 d.C. a partir de la conquista islámica de la zona.

${ }^{42}$ Saguì (1998), p. 311.

${ }^{43}$ Ocurre así con Lochner et al. (2005), quienes, en su interesante trabajo sostienen esta opinión, por más que, sin embargo, la fundamentan en los hallazgos de Crypta Balbi, para los que, precisamente en el mismo texto al que remiten, se apuesta por lo contrario.
}

$y$, de forma especial, la recuperación del teatro romano, que ha supuesto la documentación del barrio de época bizantina ya citado, ha aumentado el número de piezas ${ }^{44}$. Ahora incluso, a pesar de que la mayoría de éstas siguen concentrándose en la zona comprendida entre los cerros de la Concepción y Molinete y sobre todo en el mencionado barrio, también se dispone de algún ejemplar de la zona oriental de la península sobre la que se asienta la ciudad, ya abandonada y presumiblemente extra moenia. No faltan tampoco ejemplares en los alrededores, como el hallado junto a materiales de esta cronología en una intervención antigua en el poblado costero de Escombreras $^{45}$.

En cualquier caso, el yacimiento que ha proporcionado un mayor número de evidencias es el barrio de época bizantina. En este sentido, dentro del ingente depósito cerámico tardío documentado, su cifra resulta tan abultada que nos centramos aquí únicamente en las piezas mejor conservadas, sin entrar a cuantificar el volumen total de informes, del que habrá que ocuparse en un estudio más amplio.

A este respecto, a pesar de que entre los nuevos hallazgos se encuentra una pieza cuyas características llevan a encuadrarla en el tipo de Ephesian early Byzantine amphoriskos, objeto de atención específica en otro trabajo ${ }^{46}$, las restantes que integran el lote que ahora analizamos corresponden a la más documentada early Byzantine ampulla, que reúne la mayoría de los rasgos tradicionales atribuidos a este tipo de ungüentarios. Así, de forma homogénea, se trata de una producción caracterizada por una arcilla muy depurada, de matriz uniforme, bien calibrada, en la que los agregados, cuando son visibles, presentan un tamaño homogéneo.

Encontramos una variada coloración en función de la cocción, que va desde las tonalidades rojizas a las grisáceas o incluso negras, con frecuencia alternas en pastas mixtas. De hecho, las opciones de cocción oxidante y reductora ofrecen también una amplia gama de resultados para las superficies externas, de modo que, aun siendo mayoritaria la de color rojizo o marronáceo, no faltan los ejemplos en que sea totalmente gris (CP 4203-178-1) o incluso negra, caso este último de un interesante ejemplar cartagenero con doble sello zoomorfo, ya previamente estudiado.

Del mismo modo, los recipientes, de forma ahusada, se encuentran irregularmente engobados por inmersión, por lo general uniforme sólo hasta la mitad

\footnotetext{
${ }^{44}$ Un primer balance en Berrocal (1997).

${ }^{45}$ Murcia (2000), pp. 374-375, lám. 3.5.

46 Vizcaíno (2008).
} 
de su cuerpo, cayendo a partir de ésta toda una serie de goterones que pueden alcanzar la base. En algunos ejemplares, el engobe se encuentra también en parte del interior del recipiente, aunque apenas supera pequeños goterones en el cuello, claramente de forma accidental. De la misma forma, también suelen ser características las marcas del proceso de fabricación, consistentes en huellas fusiformes de entre 1 y $3 \mathrm{~cm}$ de largo, probablemente resultado de ese mismo proceso de cocción, cuando los recipientes permanecen uno contra el otro en el horno; otra explicación propuesta es que se trate de las improntas dejadas por el soporte usado durante el proceso de secado de las piezas, después de que éstas hayan permanecido inmersas en el mencionado engobe ${ }^{47}$. Lo cierto es que no dejan de ser muestras de una ejecución descuidada, poco atenta al aspecto final, un rasgo que se manifiesta también en la frecuente presencia de huellas digitales.

Por lo que respecta al pivote, distintas son las soluciones, no estando todas presentes en el lote que analizamos. Así, parece faltar aquí el puntal de base ligeramente cóncava que sí encontramos en otros lugares orientales, del tipo de Hierápolis o $\operatorname{Iasos}^{48}$, solución que, asociada a ejemplares no sellados que se siguen documentando en contextos avanzados como Saraçhane (s. vIII-X d.C.) y la misma Iasos (s. $\mathrm{x}$ d.C.) quizá podría ser propia de una variante tardía de estos ungüentarios ${ }^{49}$. Frente a estas excepciones, en el conjunto cartagenero predomina el pivote apuntado que no garantiza la sustentación y que unas veces es sólo terminación de la tendencia ahusada del cuerpo, mientras que en otras insinúa un pequeño pie, al modo del que desarrollará de forma más efectiva la variante del Ephesian early Byzantine amphoriskos.

También este tipo de ungüentarios se caracteriza por presentar un cuello tubular, cuidadosamente ejecutado y delimitado por una fina moldura, que algunos autores consideran destinada a servir de tope a un tapón de cierre en material perecedero ${ }^{50}$. Todas presentan borde redondeado y no apuntado, variante que conocemos en otras piezas y que normalmente limita su diámetro a los 2,4-3 cm.

Por otro lado, contrasta la delicadeza de esta parte superior del vaso con el menor detalle con el que se

${ }^{47}$ Se trata de las propuestas, respectivamente, de Lochner et al. (2005), p. 648 y Cottica (2000), p. 1002.

${ }^{48}$ Cf. Cottica (2000), fig. 1, nn. 15-17, y Baldoni y Franco (1995), fig. 4, esemplari f y g.

${ }^{49}$ Baldoni y Franco (1995), n. 2, con bibliografía sobre los yacimientos constantinopolitano y cario, respectivamente.

${ }^{50}$ Hayes (1971), p. 243. elabora el resto del cuerpo, que con frecuencia presenta un eje desviado, lo que a veces repercute en algunos pliegues para el pivote. Por su parte, el cuerpo está marcado internamente por un fuerte torneado, en ocasiones también insinuado al exterior, donde resulta habitual la presencia de grumos de arcilla.

En la misma línea, a las diferencias técnicas entre las diversas partes del cuerpo, corresponden igualmente diferencias de tamaño, de tal forma que, mientras que el grosor del borde es homogéneamente de 3-5 mm, el de la base puede llegar a los 10-12 mm, haciéndolo particularmente apto para garantizar la seguridad de contenido durante el transporte.

Por lo demás, aun cuando se trata de una producción heterogénea en lo que respecta a sus dimensiones o al grosor de sus paredes, su altura suele situarse entre los 18 y $22 \mathrm{~cm}$, de tal forma que los recipientes más grandes tienen una capacidad de entre 120 y $140 \mathrm{ml}$, en tanto que los más pequeños, de entre 80 y $100 \mathrm{ml}^{51}$.

En lo referente a la composición de la pasta, a partir de una observación macroscópica en espera de análisis petrográficos más depurados, las piezas cartageneras pueden dividirse en dos grupos que significativamente se corresponden con las dos variantes morfológicas diferenciadas para la terminación del pivote. Así, si bien ambos grupos presentan arcillas de matriz uniforme sin apenas inclusiones significativas —dado que las altas temperaturas de cocción conllevan una vitrificación que dificulta la identificación-, cabe diferenciar entre una mayoritaria serie de piezas donde encontramos partículas blanquecinas de tamaño pequeño y medio con frecuencia baja, que se asocian a pastas de coloración mixta y pivote algo insinuado, y otro grupo más minoritario, donde se encuentran ausentes aquellas partículas, con pastas de coloración uniforme y pivote escasamente desarrollado, una terminación apenas del cuerpo ahusado.

En uno y otro grupo se encuadran también algunos ejemplares con componentes algo más diversos: en el caso de la primera serie, se trata de aquellos en los que se puede rastrear la presencia de rocas metamórficas o ígneas básicas; en la segunda, de otros donde existen vacuolas, testimonio de inclusiones orgánicas, si no simplemente del proceso de cocción y la generación de burbujas, totalmente ausentes en las restantes piezas, aunque tampoco excesivamente raras para estos ungüentarios, donde en ocasiones, como ocurre con algunos de los ejemplares de Hie-

\footnotetext{
${ }^{51}$ Lochner et al. (2005), p. 648.
} 
rápolis de Frigia, se detecta la presencia de foraminíferos ${ }^{52}$

En ambas variantes de este mismo tipo de early Byzantine ampulla encontramos piezas selladas, cuyas marcas pueden aparecer también en la Ephesian early Byzantine ampulla. A este respecto, en el lote que analizamos, dentro de la tónica habitual de constituir una mínima parte del conjunto, dichas estampillas presentan cartelas sobre todo circulares y, en contadas ocasiones, con un solo registro en cada caso, de tipo rectangular y cuadrado. Faltan así las cartelas de tipo triangular, trapezoidal o en U, que esporádicamente han sido registradas en Hierápolis para los dos primeros casos y en Seleucia Sidera para el último ${ }^{53}$.

Respecto al carácter de dichos sellos, si bien la ciudad dispone de algunos de tipo zoomorfo ya publicados, que además reaparecen en otros yacimientos hispanos, caso de una pieza de Algeciras ${ }^{54}$, todos los que ahora analizamos son monogramas en caja o de bloque (en los que una letra -normalmente $\Pi$, $\mathrm{M}, \mathrm{N}$ o $\mathrm{H}-$ hace la función de marco o base cuyos trazos comparten las restantes letras) o monogramas en cruz, un tipo cuya aparición se ha fechado en un momento posterior a $518^{55}$ y que es quizá el más numeroso y extendido a todo tipo de piezas ${ }^{56}$, pero, a fin de cuentas, sólo uno más en un panorama cada vez más diverso donde encontramos desde aquellos que se caracterizan por sus ligaduras o se componen mediante iniciales, como algunos de los hallados en Hierápolis $^{57}$, a aquellos otros que bien presentan una o varias letras, se distribuyen de forma tripartita o combinan su fórmula epigráfica con animales o símbolos. Los ejemplares constantinopolitanos de Saraçhane, otros atenienses, microasiáticos, en el caso

${ }^{52}$ Para los correspondientes análisis mineralógicos remitimos a Cottica (2000), pp. 1005-1007, quien registra los últimos casos esporádicos en sus pastas U5 (anfibolitas y serpentina), U6 (basalto y piroxeno), y U7 (epidoto y foraminíferos). Acerca de la presencia de otros componentes, cf. Lochner et al. (2005), p. 648.

${ }^{53}$ Cottica (2000), fig. 1.6 y 1.2, y Laflý (2005), Abb. 4.e.

${ }^{54}$ En ambos casos se trata de un león, cf. Berrocal (1997), p. 121, y Bernal (2003), p. 34.

${ }^{55}$ La precisión cronológica se debe a Bardill (2004), pp. 47-48. La primera valoración conjunta de los sellos de ungüentarios es de Grünbart y Lochner-Metaxas (2004), pp. 180-183; cf. la clasificación de S. Metaxas (2005).

${ }^{56}$ Es el caso de la vajilla de plata, ponderales o los abundantes sellos plúmbeos. Cf. a este respecto, Cruishank Dodd (1961), Tab. I-III; C. Perassi (2002) y, especialmente, para los últimos materiales, los sellos del depósito de Crypta Balbi, de una cronología similar a la de nuestros ungüentarios, así como los de otros yacimientos, Marazzi (2001) y Touratsoglou et al. (2006). Igualmente, cf. Laurent (1952), así como el interesante Cheynet, Morrisson y Seibt (1991).

${ }^{57}$ Cottica (2000), figg. 1-2. de Antioquía de Pisidia y Seleucia Sidera, o palestinos, como los de Gerasa, entre otros, dan cuenta de estas distintas soluciones, por el momento ausentes en el panorama cartagenero ${ }^{58}$. De un modo u otro, lo cierto es que su lectura resulta bastante compleja y no está libre de equívocos, razón por la que se impone la prudencia en su interpretación ${ }^{59}$.

\subsection{ANÁLISIS DE LAS PIEZAS ${ }^{60}$}

A continuación recogemos los ungüentarios aparecidos en los últimos años, tanto en el barrio de época bizantina de Cartagena, como en algunas intervenciones arqueológicas efectuadas en otros yacimientos urbanos. Dado el ingente número de ejemplares, presentamos únicamente los que se han conservado en mejor estado, no contabilizando otro grupo de fragmentos que, en cualquier caso, habrán de tenerse en cuenta en estudios futuros para calibrar la verdadera intensidad de la presencia de estas piezas en la ciudad. También razones de índole práctica, dentro de las pautas ya mencionadas, nos llevan a estudiar únicamente los ungüentarios hallados en el teatro romano de Cartagena durante las campañas comprendidas entre los años 1993 y 2001, pero no los que han ido apareciendo con posterioridad, ya que la excavación de este yacimiento sigue aún en curso ${ }^{61}$.

En líneas generales, cabe destacar que aparecen tanto en los comienzos de la fase de presencia institucional bizantina (UU.EE 6167, 6447, 6487), como en pozos datados en pleno floruit de ésta (UU.EE 4466, 4488, 6492, 9792), mas algunos también en los momentos últimos de la secuencia del barrio, en estratos de destrucción (UE 3156), cuando no abandono y colmatación de las viviendas (UU.EE 4313, 3637), en cualquier caso, como vemos, en un reparto cuantitativo tan homogéneo que apenas permite señalar tendencia alguna.

${ }^{58}$ Respecto a los primeros, cf. Harrison (1986), p. 9, fig. 2. Recoge las piezas del sudoeste turco Laflý (2005), Abb. 4-5. Para los ungüentarios palestinos, Uscatescu (1996), p. 347, fig. 77.

${ }^{59}$ Para la lectura de este tipo de monogramas, Fink (1981). Alerta sobre los excesos en la lectura de estos sellos, Baldoni (1999).

60 Tres de éstas (CP 4488-178-1, CP 6167-178-1 y CP 4203-178-1) han sido presentadas de forma preliminar en el marco de sendas exposiciones sobre la presencia bizantina en España (Bádenas de la Peña 2003); cf. Bizancio en Carthago Spartaria. Aspectos de la vida cotidiana. Catálogo de la Exposición, Murcia 2005, n. ${ }^{\circ}$ 54, p. 117), quedando pendiente el estudio que ahora acometemos. Igualmente, la última pieza que incluimos en nuestro catálogo, también ha sido objeto de publicación previa (Berrocal 1997, p. 122, lám. 1.7), ciñéndonos ahora únicamente al análisis paleográfico de la misma. 


\section{EJEMPLARES HALLADOS EN EL TEATRO ROMANO}

CAMPAÑA DE 1993

\subsubsection{CP 4203-178-1 (Figs. 4.1 y 8.1)}

La pieza fue hallada en el interior de un relleno de la fase islámica, que contenía, sin embargo, abundante material de época bizantina. Conserva solamente el ápice, y es posiblemente uno de los más singulares del conjunto, no tanto por sus dimensiones, sólo algo su-
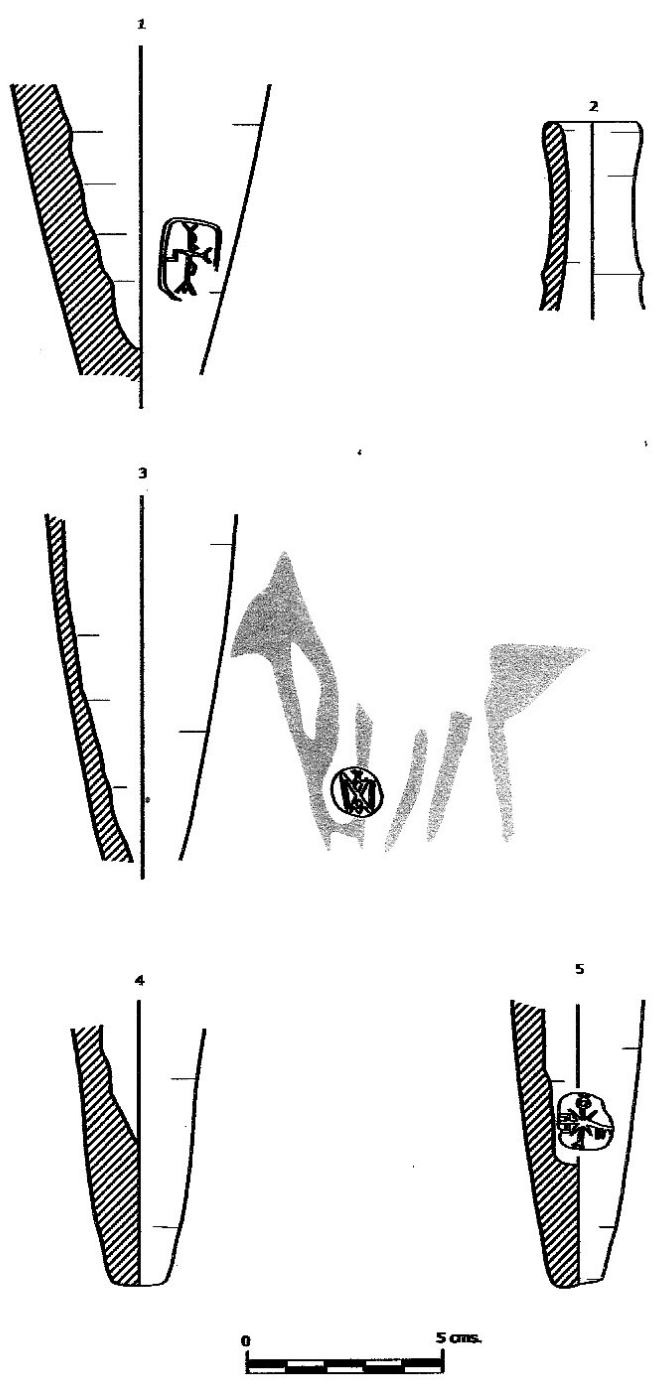

Fig. 4. Ungüentarios hallados en el teatro romano de Cartagena. N. ${ }^{\circ} 1$ (CP 4203-178-1), 2 (CP 4313-178-1), 3 (CP 5234178-1), 4 (CP 5301-178-1), 5 (CP 4567-178-1). periores a las del resto, como por su cocción reductora, fruto de la que resultan superficie y pasta gris, en las que no se advierte ninguna inclusión significativa. Debemos destacar en cambio el tratamiento del cuerpo, cuya superficie se presenta cuarteada, particularidad que no hemos constatado en ningún otro ejemplar. De la misma forma, a pesar de que sólo conservemos el ápice, todo lleva a pensar que no se le ha aplicado engobe, puesto que faltan los típicos goterones que desde la mitad superior del cuerpo llegan a descender hasta la misma base. En cuanto a ésta, se encuentra fracturada, si bien deja entrever el desarrollo de pie, quizá ofreciendo una sustentación más eficaz que la que encontramos en las otras piezas.

Por otra parte, el ungüentario fue sellado con un monograma de cartela rectangular deteriorada en el extremo inferior derecho y más hundida en el lateral izquierdo. Las letras se leen con claridad a pesar de tener menor profundidad que la propia cruz. Llama la atención la primera letra (si empezamos a leer, como es habitual, por la situada a la izquierda), que parece trepar hasta el extremo de la cruz y que podría ser una $\Gamma$, con uno de sus trazos confundido en la prolongación del brazo de la $\mathrm{cruz}^{62}$. En la vertical se lee B P A, en el extremo derecho, la lectura es más dudosa: $\Sigma$ triangular o $\Lambda$. En la parte superior, encontramos la esperable $Y$, que hace las veces de ligadura $\mathrm{OY}$, indicando así el caso genitivo en el que se suelen inscribir estos nombres. No hemos encontrado monogramas similares, ni en ungüentarios ni en otros soportes, pero no está fuera de lugar leer en este monograma el nombre de Gabriel, que responde con precisión a las letras identificadas. Lo que es más, puesto que —como veremos a propósito de los ungüentarios 4.1.6 y 4.1.19- no es raro encontrar en los monogramas cruciformes de los ungüentarios sellos con la indicación de «del prefecto», resulta razonable identificar el Gabriel de este sello con un eparco de Constantinopla atestiguado en 543, cuyo nombre está recogido en genitivo con la forma $\Gamma A-$ $\mathrm{BPIH} \Lambda \mathrm{IOY}^{63}$. En las conclusiones exploraremos el alcance de esta propuesta de identificación.

\footnotetext{
${ }^{61}$ En nuestro estudio hemos pretendido conceder especial importancia al depósito cerámico en el que se integran los ungüentarios, cuya bibliografía básica recogemos únicamente en esta nota, evitando reiterar las citas. Para la vajilla en terra sigillata Africana D, seguimos la tradicional tipología de Hayes (1972); con las nuevas observaciones sobre la cronología aportadas por Tortorella (1998). Para el material anfórico, hemos seguido las obras de Keay (1984) y Remolà (2000). En cuanto a la cerámica de producción local, utilizamos la tipología de Laíz y Ruiz (1988).

${ }_{62}$ Encontramos una solución similar para incluir gamma en el sello n. ${ }^{\circ} 106$ de Cheynet (1994) 448.
} 


\subsubsection{CP 4313-178-1 (Fig. 4.2)}

La pieza fue hallada en el estrato de colmatación de la habitación $n .^{\circ} 10$, anexa a aquella otra en la que se recuperó un ejemplar de coraza laminar, datado entre el siglo vi avanzado y la siguiente centuria ${ }^{64}$. Entre el material cerámico del estrato, aparte de algún ánfora norteafricana (Keay LXI-LXII), sólo cabe destacar la presencia del ánfora oriental LRA 1 / Keay LIII, así como de algunas ollas y cazuelas de producción local.

En cuanto al ungüentario, resta únicamente la boca.

\section{CAMPAÑA DE 1995}

\subsubsection{CP 5234-178-1 (Figs. 4.3 y 8.3)}

A pesar del deficiente estado de conservación de la pieza, fragmentada y erosionada, se trata posiblemente de una de las más significativas del lote que presentamos: por un lado, porque presenta un tipo de sello, con monograma en caja, apenas registrado en la ciudad (cf. addendum) y en conjunto, al parecer, tampoco el más frecuente en el amplio mapa de distribución mediterránea de estas piezas; por otro, porque estratigráficamente se encuentra también entre los ungüentarios de posible datación más temprana. Resulta sugerente, además, poner en conexión ambas particularidades, si bien creemos que es importante no perder de vista otra serie de datos.

El ungüentario formaba parte de un relleno anterior a la etapa bizantina (fase 9 de la excavación), situado en el exterior de la habitación n ${ }^{\circ} 27$ del barrio de dicha fase. En este sentido, a pesar de la estratigrafía, resulta dudosa su datación en la mencionada fase 9 , fechada en la primera mitad del siglo vI d.C., en tanto el depósito cerámico muestra un porcentaje considerable de intrusismos, entre los que destacan algunas formas propias del último cuarto del siglo vil d.C., como el tipo Hayes $107^{65}$.

Respecto a la pieza, como dijimos, sólo conserva parte del cuerpo, habiendo perdido el pivote. Una particularidad de la manufactura reside en el tratamiento de su superficie, en la que, si bien igualmente afectados por el estado de conservación, se aprecian restos de impresiones paralelas, a veces coincidentes con el torneado interno. Por lo demás, el ungüen-

\footnotetext{
${ }^{63}$ Feissel (1986), p. 120, n. 3; Martindale (1992), p. 498.

${ }^{64}$ Vizcaíno (2007) y (2007bis).

${ }^{65}$ Tortorella (1998), p. 68.
}

tario es fruto de una cocción oxidante, presentando superficie y pasta de tonalidad beige, en la que también, en esta última, se aprecia un minúsculo núcleo ceniciento. Apenas se pueden distinguir inclusiones significativas más que algunas partículas blancas de tamaño pequeño y carácter esporádico, o tan sólo una, de color negro, visible en superficie y algo significativa, dado que, dentro de nuestro análisis macroscópico, tan sólo la documentamos aquí.

El monograma en caja que conforma el sello se enmarca en una cartela circular que lo ciñe estrechamente. Destaquemos que el trazo del aspa central y de las verticales laterales es similar a una cinta (más ancho que profundo). La letra que sirve aquí de apoyo o marco al resto de las letras es una $\mathrm{M}$, cuyos trazos oblicuos se prolongan hasta formar un aspa que a su vez forma en la parte inferior la letra A, cerrada en pico (en realidad, una segunda aspa). Son las únicas letras distinguibles en el monograma, aparte de una tercera aspa superior en la que podemos leer la terminación en OY, ya mencionada en otra morfología. Monogramas que responden al mismo esquema, realmente exitoso, se han encontrado en el yacimiento valenciano de Punta de l'Illa de Cullera ${ }^{66}$, así como en Iasos y Cnido ${ }^{67}$. Del mismo modo, sellos muy similares se encuentran en la capital del Imperio (Depósito 30 de Saraçhane, s. VII ${ }^{68}$ ), Éfeso ${ }^{69}$ y Antioquía de Pisidia ${ }^{70}$.

Esta misma disposición de las letras M A sirve de base al monograma del emperador Mauricio en soportes como monedas, recipientes de plata y ladri$1 \operatorname{los}^{71}$, aunque en el caso de los ungüentarios la ausencia de otras letras que apoyen la lectura del nombre del emperador impide justamente ésta. Sin embargo, sí es cierto que los monogramas en caja con M A aparecen habitualmente en ladrillos constanti-

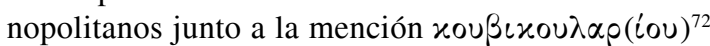

${ }^{66}$ García y Rosselló (1993), fig. 2.2-3. La calidad poco detallada de la reproducción no permite considerar la identidad de los sellos. Paralelos más cercanos han aparecido en Éfeso, Constantinopla y Atenas (Metaxas 2005, p. 81, KatNr. 21; Taf. 2).

${ }^{67}$ Baldoni y Franco (1995), Abb. 6; Eisenmenger y Zäh (1999), Tav. 1

${ }^{68}$ Hayes (1992), p. 9, Pl. 16.11 y 12.

${ }^{69}$ Metaxas (2005), p. 79, n. ${ }^{\circ} 6$ (KatNr. 10; Taf. 2), que menciona la presencia de un sello similar en Berenice; cf. Riley (1979), Taf. 32, n. ${ }^{\circ} 1033$.

${ }^{70}$ Laflý (2005bis), p. 180, y reproducción de los sellos en Abb. 8 y 9. Laflý los fecha a mediados del s. VII.

${ }^{71}$ Para cada uno de los mencionados materiales, cf. respectivamente, Feissel (1986), p. 135, n. ${ }^{\text {o } 30-31, \text { Cruishank }}$ Dodd (1961), pp. 118-121 (n. 30 y 31), y Bardill (2004), pp. 47 y 364, n. $^{\circ} 1348-50$.

${ }^{72}$ Bardill (2004), Tab. 27, n. ${ }^{\circ} 11$, Monogram n. ${ }^{\circ} 1346$ y 1347 
o precediendo a la mención del reinado de Mauricio (દ่ $\pi i \mathrm{M}$ aupıxiou $)^{73}$, sin que Bardill haya podido conjeturar una explicación sobre su valor. Si lo que esconde este monograma en caja tan difundido es el nombre de un eparco de Constantinopla -como sugieren otros sellos aquí examinados-, hay que mencionar que en el s. vi está atestiguado uno de nombre Martino/Martiniano (MAPTINOY/MAPTINIANOY) en pesos-patrón de vidrio $^{74}$.

\subsection{4. $\quad$ CP 5301-178-1 (fig. 4.4)}

En este caso el ejemplar fue recuperado en el interior del relleno de una fosa de expolio practicada en la habitación n. ${ }^{\circ} 24$ del barrio de época bizantina. Éste se caracterizaba por su amplia cronología, incluyendo, además de un porcentaje no significativo de piezas residuales, materiales que cubrían desde la etapa bizantina a la islámica.

El ungüentario conserva únicamente el pivote, de cierto desarrollo, si bien tampoco garante de sustentación $^{75}$.

\subsection{5. $\quad$ CP 4567-178-1 (Figs. 4.5 y 8.5 )}

La pieza fue recuperada en un pavimento de la fase islámica (siglos XII-XIII). A pesar de la estratigrafía, el material cerámico recuperado se enmarca claramente dentro de la fase bizantina, contando con gran parte de las producciones y formas características de ésta.

El ungüentario conserva únicamente su ápice, rematado en base anular con plano ligeramente inclinado. Cuenta con pasta de tipo mixto, con núcleo central ceniciento, sin que se distinga inclusión alguna significativa. En cambio, su superficie muestra una coloración marronácea en la que, junto a las manchas de ahumado y rugosidades varias, cabe destacar la presencia de un goterón de engobe

Por otro lado, la pieza presenta un sello con cartela circular irregular, fruto del estampillado defectuoso, deformado en especial en su parte izquierda. La estampación no es excesivamente profunda, pero permite leer con claridad las letras E (invertida y con forma rectangular), П (que parece prolongar el trazo superior en un ápice), una gran X central de trazado ancho y la

\footnotetext{
${ }^{73}$ Bardill (2004), Monogram n. ${ }^{\circ} 1373$.

${ }^{74}$ Martindale (1992), pp. 838-839 y Monogram n. ${ }^{\circ} 415$.

${ }^{75}$ No nos ha sido posible analizar directamente esta pieza, moviéndonos únicamente con el material gráfico disponible acerca de la misma.
}

ligadura de la terminación OY (con el círculo inferior ligeramente triangulado y la $\mathrm{V}$ superior corta y abierta) en el extremo superior. En el inferior, la comparación con otros sellos permite asegurar la presencia de A. Se trataría, pues, del monograma ЕПАРХОY, que encontramos también en otra pieza de Cartagena, la de calle Beatas y que se imprimía en ungüentarios y otros objetos. De los sellos que hemos podido estudiar, el nuestro se acerca mucho a uno encontrado en San Polieucto en un contexto del s. VIII (pero probablemente residual) y a un ungüentario de Iasos datado en el s. $\mathrm{VII}^{76}$. En las conclusiones abordaremos el significado de este sello.

\section{CAmpaña de 1996}

\subsection{6. $\quad$ CP 4868-178-1 (Figs. 5.6 y 8.6)}

El ejemplar fue hallado en el interior del relleno de una gran fosa (UE 4855) situada sobre la antigua orchestra. Dicha fosa contenía un amplio depósito de materiales datados entre los siglos VI y xI d.C., si bien acaparaban el protagonismo los restos de época bizantina, entre los que hay que destacar tipos en terra sigillata Africana D, como el cuenco Hayes 80B/99, el plato Hayes 104, o la fuente Hayes 105.

En cuanto al ungüentario, del que resta únicamente el ápice, presenta una coloración beige recorrida por goterones de engobe, vacuolas apenas destacables, o inclusiones blanquecinas de tamaño mínimo en frecuencia baja. La pasta es de tipo mixto, con núcleo central gris.

El sello, del que se conserva aproximadamente la mitad derecha, está inscrito en lo que pretendía ser un rectángulo, de esquinas redondeadas y forma irregular. El monograma, cuyas letras apuran el espacio que se les concede, es cruciforme y en el estado actual la única letra segura es la X central, bien marcada sobre el cruce central. A su derecha, tres trazos en zig-zag pueden ser una $\mathrm{H}$. En la parte inferior, sólo se conserva de la letra correspondiente un trazo inclinado que podría responder a $\mathrm{A}, \Delta$ o $\Lambda$. En el extremo superior, muy deteriorado, algunos indicios sugieren la presencia habitual de la ligadura -OY. Nos encontramos, pues, ante un monograma cruciforme

${ }^{76}$ Hayes (1992), p. 9 n. ${ }^{\circ} 44$, aunque aquí E no está invertida y la $\mathrm{X}$ no forma parte del monograma, pero la ligadura OY es redonda como en CP 4567. Por otra parte, la diferencia con el unguentarium de Iasos es la forma triangular de OY; cf. Baldoni y Franco (1995), fig. 6, n. ${ }^{\circ}$ 1; Baldoni (1999), fig. 1. 
en el que, a pesar de su conservación fragmentaria, no es arriesgado leer el nombre MIXAH $\Lambda \mathrm{IOY}^{77}$.

\subsubsection{CP 6167-178-1 (Fig. 5.7)}

Este ungüentario fue recuperado en el interior del relleno de una fosa de expolio de la habitación n. $^{\circ}$ 29 del barrio de época bizantina. Desde el punto de vista estratigráfico, junto al ejemplar CP 5301-1781 , es una de las más tempranas del lote que presentamos. Lamentablemente, el exiguo y deteriorado depósito cerámico en el que se integraba poco puede colaborar a corroborar dicha realidad.

Sorprende en dicho panorama el buen estado de conservación del ungüentario, que mantiene gran parte de su cuerpo. Se engloba en el tipo de early Byzantine ampulla, si bien en la variante apenas representada en el lote cartagenero, cuyo pivote presenta escaso desarrollo, siendo apenas únicamente la terminación ahusada del cuerpo. Como ya se comentó, a tal particularidad morfológica acompañan también otras desde el punto de vista técnico, tales como una pasta uniforme de coloración beige, no mixta, y la presencia de pequeñas vacuolas. Dicha superficie, por lo demás, presenta también color beige, habiendo recibido engobe en la parte superior del cuerpo, donde también se advierten dos impresiones fusiformes, que desciende en goterón hasta la base.

\subsection{8. $\quad$ CP 4466-178-1 (Fig. 5.8)}

Este pivote de ungüentario se encontraba en el interior del relleno de un pozo de época bizantina (UE 4467) que únicamente proporcionó material de cronología genéricamente tardía.

De la pieza sólo se conserva su terminación con pie algo desarrollado que, al menos morfológicamente, puede ser incluido en el grupo de early Byzantine ampulla $^{78}$.

\subsubsection{CP 4488-178-1 (Fig. 5.9)}

Este ungüentario, uno de los mejor conservados del lote que presentamos, fue hallado en el interior

\footnotetext{
${ }^{77}$ Un monograma muy similar en Martindale (1992), Mo-

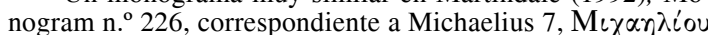
бxpíßovos (med. s. vI-med. s. vII). Conocemos dos funcionarios $\alpha \pi$ ò $\varepsilon \pi \alpha \rho \chi \omega \nu$ de nombre Miguel (ibidem, p. 889, Michael 6 y 9).

${ }^{78}$ No nos ha sido posible analizar directamente esta pieza, moviéndonos únicamente con el material gráfico disponible acerca de la misma.
}

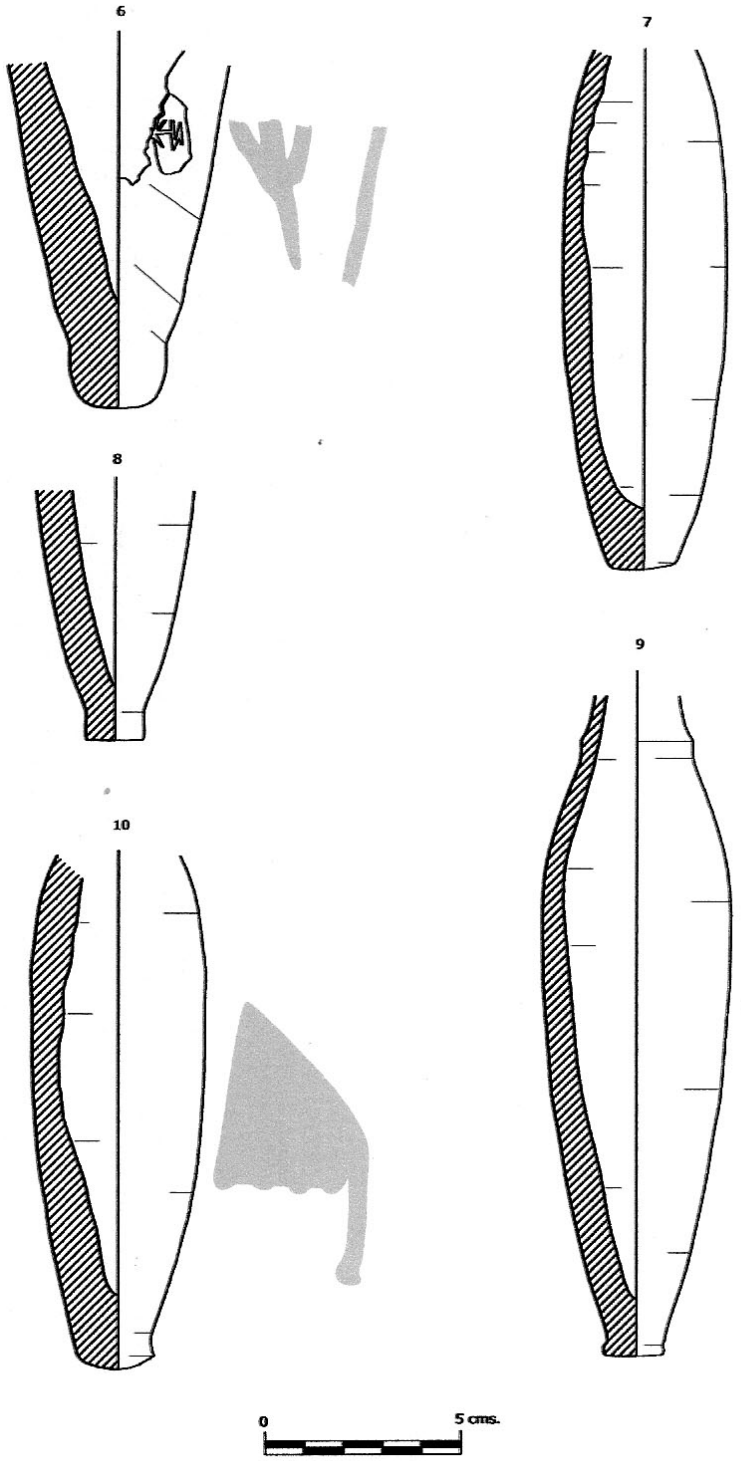

Fig. 5. Ungüentarios hallados en el teatro romano de Cartagena. N. ${ }^{\circ} 6$ (CP 4868-178-1), 7 (CP 6167-178-1), 8 (CP 4466178-1), 9 (CP 4488-178-1), 10 (CP 4847-178-1)

de una fosa de época bizantina en la zona occidental de la plaza porticada del mercado. Afortunadamente, el material cerámico que lo acompañaba nos aporta un margen cronológico preciso, pues, junto a ánforas orientales de cronología genéricamente tardía (LRA 1 / Keay LIII), también aparecen algunos de los tipos de la vajilla fina norteafricana más característicos (Hayes 101, Hayes 105)

El ungüentario, al que le falta únicamente la boca, ha sido elaborado con una cocción oxidante, fruto de la que resultan superficie y pastas rojizas. Por su 
parte, el pivote se encuentra algo desarrollado, pero no es capaz de proporcionar sustentación.

\subsubsection{CP 4847-178-1 (Fig. 5.10)}

El ungüentario formaba parte del relleno de una fosa (UE 4855), donde, junto una amplia representación de las producciones cerámicas de época islámica, encontramos un característico depósito de época tardoantigua.

El ejemplar ha perdido la parte superior y es fruto de una cocción reductora. La pasta presenta una coloración uniforme, con una arcilla muy depurada. En su superficie, de ejecución descuidada, son apreciables algunas vacuolas, no abundantes pero sí en determinados casos significativas, dado que su grosor y profundidad llevan a pensar en la presencia de materia orgánica más que en irregularidades fruto del proceso de cocción. En el mismo sentido, una observación macroscópica también permite detectar las habituales partículas blanquecinas de tamaño pequeño y medio, registradas con intensidad moderada.

\subsubsection{CP 3156-178-1 (Fig. 6.11)}

Este pivote de early Byzantine ampulla integraba el nivel de destrucción de la habitación n. 35 del barrio de época bizantina, levantada sobre la media cavea del edificio augusteo. Dicha destrucción, que parece corresponder a la que llevan a cabo las tropas del rey visigodo Suintila c. 625, se puede datar por la presencia de un variado repertorio de formas cerámicas, entre las que, para la vajilla fina, cabe destacar los tipos Hayes 99 C, 80 B/99, 104 C o 105 realizados en terra sigillata Africana $\mathrm{D}$, acompañados de las ánforas más características de procedencia norteafricana y oriental, sea el caso de los tipos Keay LXI-LXII, spatheia y LRA 1 / Keay LIII, respectivamente, esta última además, con su variante de producción local que la toma como prototipo.

El ejemplar conserva sólo el pivote, apenas desarrollado, sin pie alguno, terminando únicamente la tendencia ahusada de las paredes.

\section{CAMPAÑA DE 1997}

\subsubsection{CP 3416-178-1 (Fig. 6.12 y 8.12)}

Este ungüentario fue localizado fuera de su contexto original, en concreto, en un relleno de abandono de las habitaciones de época bajomedieval construidas junto a la Catedral Vieja.

La pieza, que conserva únicamente el fondo, cuenta con superficie beige, así como pasta alterna, de núcleo central gris tenue, sin apenas contraste, y en donde se aprecian partículas blanquecinas de tamaño mínimo en intensidad baja.

La inclusión del sello cruciforme es anómala: si identificamos el signo que está en la parte inferior izquierda con la terminación -OY, que debería encontrarse en el extremo superior, entonces el monograma está prácticamente invertido. Acorde con esta estampación descuidada es la propia morfología del sello, cuya única letra realmente perfilada es una gran E rectangular. En las dos restantes, sólo se puede tener certeza de la presencia de un elemento de base circular, que sugiere las letras $О \theta \Phi$ (descartamos sigma lunar [C], infrecuente en estos sellos); en el extremo derecho, podría tratarse de $\Phi$, aunque la hipotética asta estaría torcida y no es imposible que se trate de una irregularidad del sello. Por lo que respecta al elemento inferior, resulta tentador ver en él una $\mathrm{P}$ y leer EФОРОY, pero la verdad es que otras lecturas

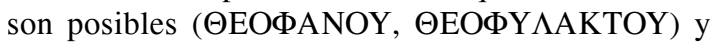
todas hipotéticas ${ }^{79}$.

\subsubsection{CP 3637-178-1 (Fig. 6.13)}

El ungüentario fue recuperado en el relleno de abandono depositado en el interior de la habitación n. ${ }^{\circ} 14$ del barrio de época bizantina, anexa a aquellas donde se documentaron restos de equipamiento defensivo, como puntas de flecha de tipo ávaro o una coraza laminar $^{80}$. Lamentablemente, sin embargo, el relleno en el que se encontraba la presente pieza apenas aportó material significativo.

Tampoco el ungüentario se encuentra entre los más interesantes, restando únicamente el pivote con las habituales características de esta producción.

\section{CAMPaÑa DE1999}

\subsubsection{4. $\quad$ CP 6492-178-1 (Fig. 6.14)}

Recuperado en el interior del relleno de un vertedero localizado sobre la habitación n. ${ }^{\circ} 69$ del barrio de época bizantina, fue hallado junto a las formas más habituales de la vajilla fina norteafricana (Hayes 99,

\footnotetext{
${ }^{79}$ Hay un Teofilacto $\alpha \dot{\pi} \dot{o}$ ċ $\pi \dot{\alpha} \rho \chi \omega \nu$ atestiguado en el s. VII (Martindale 1992, p. $1312=$ Zacos 1105)

${ }^{80}$ Vizcaíno (2007) y (2007bis).
} 
102, Hayes 104, 109), ánforas africanas (Keay LXILXII, spatheia), orientales (LRA 1 / Keay LIII), de producción local, o una olla de procedencia incierta con paralelos en la segunda mitad del siglo viI d.C. ${ }^{81}$.

En cuanto al ungüentario, en su superficie, de coloración beige, se advierten inclusiones blanquecinas de tamaño mínimo e intensidad baja, así como alguna esporádica partícula dorada tono mate, de tamaño pequeño. Por otra parte, su pasta es uniforme en uno de sus lados y en el otro alterna, igual que ocurre en la boca.

\subsubsection{CP 9265-178-1 (Figs. 6.15 y 8.15)}

Hallado en un relleno datado estratigráficamente entre la fase bizantina y la posterior islámica, junto a diversos tipos de la vajilla en terra sigillata Africana D (Hayes 99B/C, 80B/99, 101, 104C), lucernas y ánforas norteafricanas (Keay LXI, XXXII, spatheia), orientales (LRA 1 / Keay LIII, LRA 2 / Keay LXV, LRA 3/ LIV bis, LRA 4/ LIV) o cerámica de cocina de producción local.

El ungüentario conserva únicamente el pivote, apenas desarrollado, a modo de simple terminación ahusada, con pasta de coloración beige uniforme, no alterna, así como superficie igualmente beige con goterones de engobe, en la que están ausentes las inclusiones blanquecinas.

Como sucedía con el ejemplar CP 3416, este sello también ha sido estampado de un modo descuidado y presenta lo que debería ser la parte superior en el lado inferior izquierdo. En este caso, sin embargo, lo que nos impide leer la totalidad del sello es que no se ha acabado de estampar por la parte derecha. El marco es circular, ligeramente más estrecho por la parte central, sin duda porque la letra del extremo izquierdo (I) permitía que el círculo se estrechara. Esta morfología confirma que primero se diseñaban las letras y luego se rodeaban estas. La forma superior es la ligadura OY, omnipresente en los sellos de la presente muestra; la inferior debería poder leerse como $\Phi$ (en los monogramas cruciformes esta letra suele ser un círculo alrededor del centro de la $\mathrm{cruz}^{82}$ ) y toca el único trazo conservado de la letra del extremo derecho, una línea oblícua de notable anchura que en el molde original se cruzaría con el extremo derecho. Esta letra derecha, estampada parcialmente, podría ser $\mathrm{K}$ o E invertidas, o bien $\mathrm{X}$ o $\Lambda$, aunque no parece que hubiera realmente espacio para ellas. De ser lambda la letra derecha, podría considerar que el monograma encie-

\footnotetext{
${ }^{81}$ Murcia y Guillermo (2003), p. 184, fig. 8.70.

${ }^{82}$ Fink (1981), pp. 79-80, n. ${ }^{\circ} 23$ y 31.
}
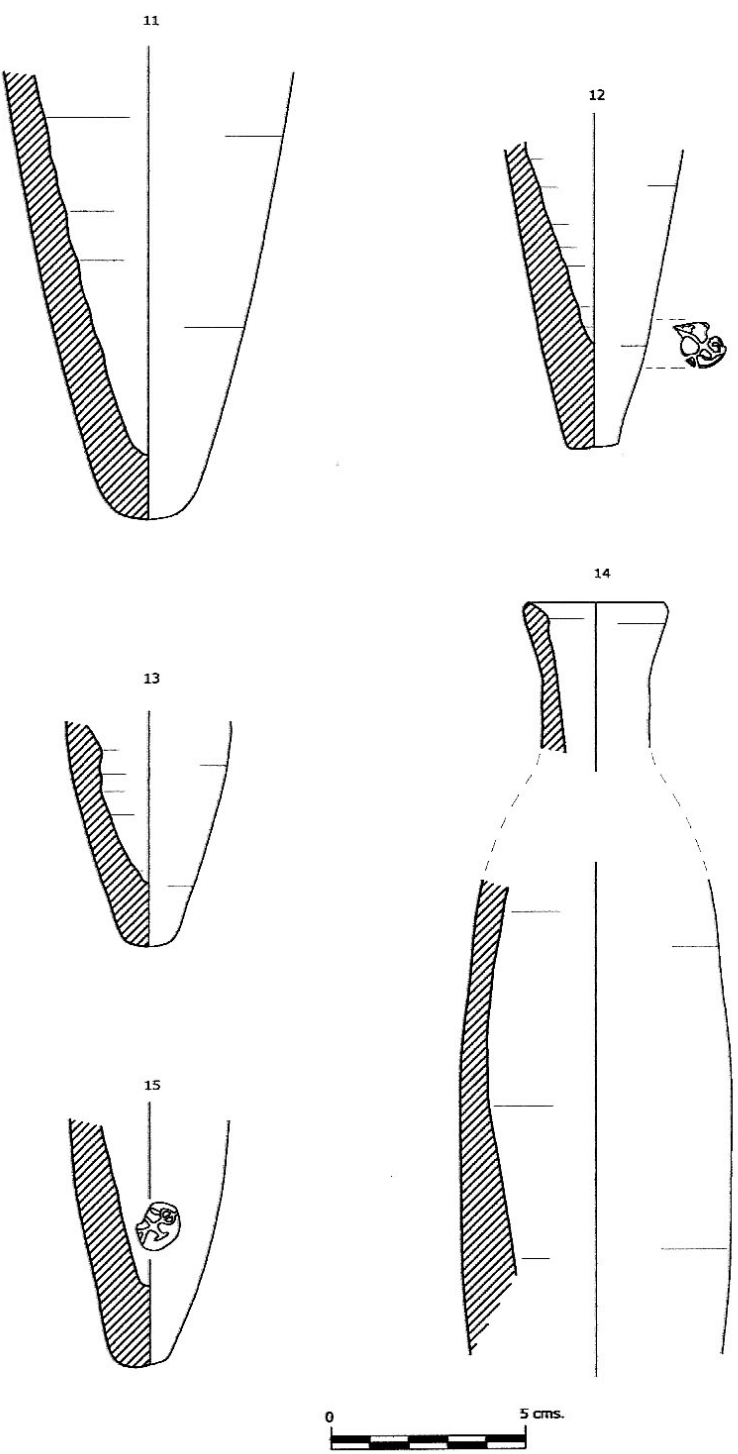

Fig. 6. Ungüentarios hallados en el teatro romano de Cartagena. N. ${ }^{\circ} 11$ (CP 3156-178-1), 12 (CP 3416-178-1), 13 (CP 3637-178-1), 14 (CP 6492-178-1), 15 (CP 9265-178-1).

rra aquí el nombre de Philippus (ФІАІППОY), un eparco de Constantinopla en el s. vi/viI, del que se conserva un monograma cruciforme en un peso de vidrio, que no coincide con el nuestro ${ }^{83}$.

\subsubsection{CP 6447-178-1 (Fig. 7.16)}

Fue recuperado en un relleno constructivo de la habitación n. ${ }^{\circ} 67$ del barrio de época bizantina, sobre la antigua porticus post scaenam.

\footnotetext{
${ }^{83}$ Martindale (1992), p. 1026.
} 


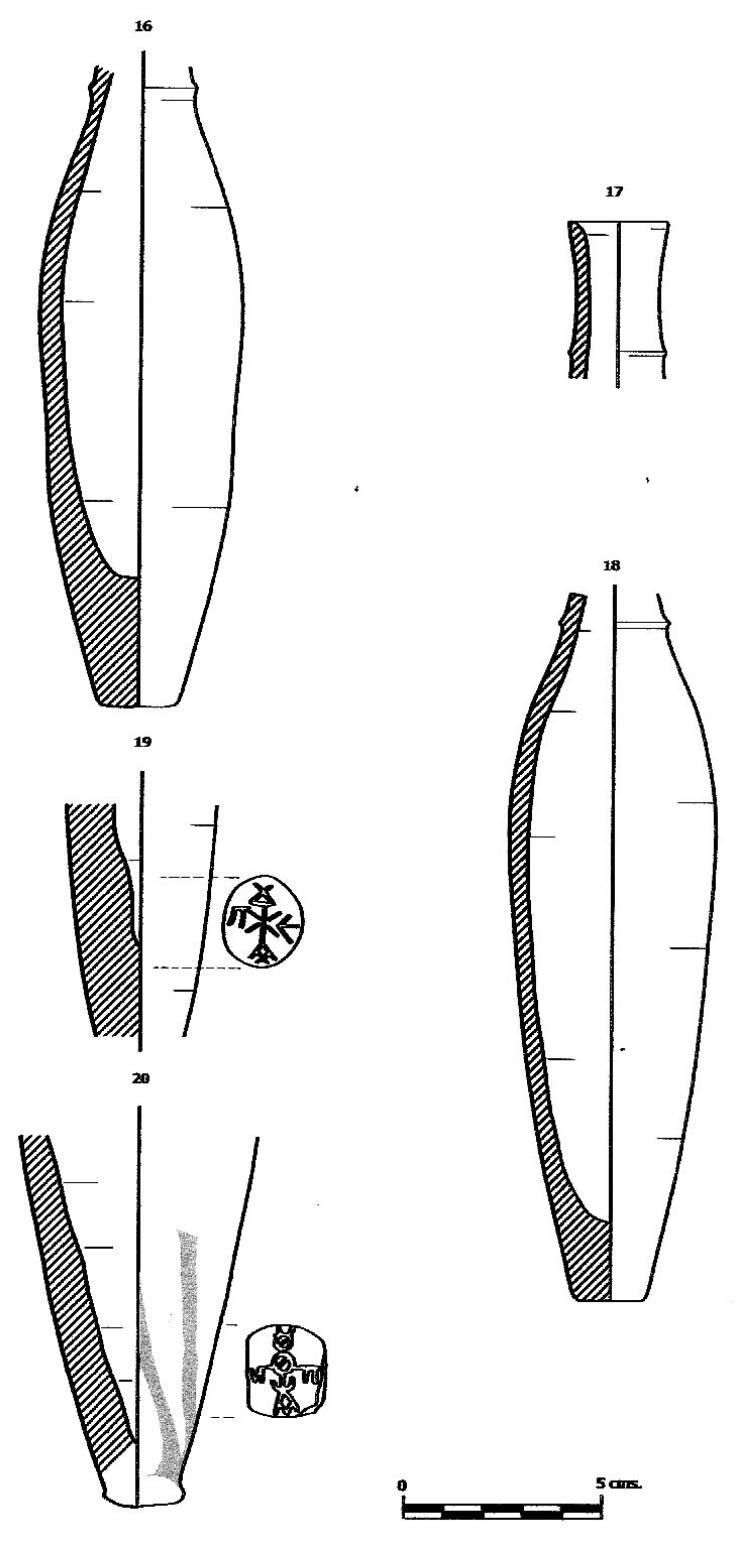

Fig. 7. Ungüentarios hallados en el teatro romano de Cartagena y otros yacimientos de la ciudad. N. ${ }^{\circ} 16$ (CP 6447-1781), 17 (CP 6487-178-1), 18 (CP 9272-178-1), 19 (B-03/1001178-1), 20 (M-90/3-IIB).

El depósito cerámico no se aparta de lo habitual en esta fase, salvo en que sí se registra una variada presencia de los contenedores orientales (LRA $1 /$ Keay LIII; LRA 2 / Keay LXV, LRA 3 / Keay LIV bis o LRA 4 / Keay LIV), mas sin eclipsar la pujanza norteafricana, tanto en la vajilla de mesa (Hayes 80 B/99, 99, 100, 104) como en las ánforas (Keay LXI, LXII, spatheia).

El ungüentario se ha conservado prácticamente completo, faltándole simplemente la boca, de la que únicamente resta el arranque del cuello. La pieza, en cuya superficie se insinúa el fuerte torneado interno, destaca por estar pasada de cocción, circunstancia que afecta tanto a su superficie como a su pasta mixta. En ambas se pueden apreciar inclusiones blanquecinas de pequeño tamaño en intensidad moderada.

\subsubsection{CP 6487-178-1 (Fig. 7.17)}

Este cuello de ungüentario fue hallado en el interior de un relleno depositado sobre la habitación $n$. $^{\text {o }}$ 69 del barrio de época bizantina. Se documentó junto a algunos de los tipos más habituales de la vajilla fina norteafricana (Hayes 91, 99, 101) o ánforas de procedencia oriental (LRA 1 / Keay LIII, LRA 2 / Keay LXV, LRA 3 / Keay LIV bis, LRA 4 / Keay LIV).

La pieza es fruto de una cocción reductora, con pasta mixta, de núcleo central ceniciento, advirtiéndose minúsculas inclusiones blanquecinas en intensidad baja, que también afloran a la superficie.

\section{CAMPAÑA DE 2001}

\subsubsection{CP 9792-178-1 (Fig. 7.18)}

Formaba parte de un basurero que colmataba una fosa de expolio de época bizantina (UE 9794), asociándose a ánforas orientales (LRA 1 / Keay LIII y LRA 4 / Keay LIV) y cerámica de cocina de producción local.

El ejemplar se conserva prácticamente íntegro, a excepción del cuello. Pertenece a la variante de pivote de escaso desarrollo, contando con superficie beige y pasta muy depurada, mixta, de núcleo central ceniciento.

\section{EJEMPLARES HALLADOS EN OTROS PUNTOS DE LA CIUDAD}

\subsubsection{B-03/1001-178-1 ${ }^{84}$ (Figs. 7.19 y 8.19 )}

El ungüentario fue recuperado en un nivel superficial, fuera de contexto, en un solar de la calle Beatas, cercano a la necrópolis tardía ${ }^{85}$. Conserva única-

\footnotetext{
${ }^{84}$ Queremos agradecer al arqueólogo D. A. J. Murcia, responsable de la excavación de dicho yacimiento, las facilidades dadas para el estudio de la pieza.

${ }^{85}$ En dicho solar pudo documentarse un sector urbano de época altoimperial, compuesto por parte de la trama viaria, así como un conjunto doméstico (Murcia 2005).
} 
mente el pivote, si bien ha perdido su remate. Fruto de una cocción oxidante, presenta superficie de color marrón, con pasta mixta de núcleo ceniciento. Elaborado en una arcilla depurada, como es habitual, la observación macroscópica no permite diferenciar inclusiones significativas aparte de alguna esporádica partícula blanquecina de tamaño mínimo.

La pieza presenta un sello de cartela circular, de ejecución cuidada, que mantiene cierta distancia de cortesía con las letras que encierra. En su interior un monograma cruciforme en el que falta el travesaño horizontal, de modo que las letras laterales quedan colgadas. Se percibe claramente una $E$ triangular, $\Pi$ con la horizontal sobresaliendo ligeramente por la parte derecha, A inferior en la que el interior del ángulo que constituye el módulo de esta letra alberga una cruz cuyos trazos inferiores superan el espacio del citado módulo. En la parte superior, la ligadura del genitivo -OY muy triangulada. Nos encontramos, pues ante un nuevo ejemplar del monograma ЕПАРХОY, próximo a dos ejemplares de ungüentarios de $\mathrm{S}$. Polieucto, cuya fecha no ayuda a precisar el contexto ${ }^{86}$.

\subsubsection{0. $\quad M-90-3-I I b$ (Figs. 7.20 y 8.20)}

Publicada ya previamente en el marco de un trabajo en el que se analizaba el contexto en el que apareció, así como sus características morfológicas, volvemos a ocuparnos de esta pieza hallada en calle Mayor, esquina calle Comedias, en plena zona portuaria de la Carthago Spartaria bizantina, para un estudio paleográfico del sello que presenta ${ }^{87}$.

En efecto, este monograma cruciforme se inserta en una cartela rectangular ligeramente trapezoidal, de impresión más marcada en la parte inferior y derecha. La disposición de las letras se diferencia de la de los restantes sellos cartageneros en la acumución de formas en el extremo inferior del eje verti$\mathrm{cal}^{88}$. La ejecución del sello sugiere retoques sobre la forma después de impresa con intención de borrar las barras cruzadas en la zona central dentro del círculo que lo rodea, en el extremo superior cuando atraviesa lo que debería ser una ómicron y en el extremo izquierdo de la barra horizontal. El resultado es

${ }^{86}$ Cf. Hayes (1992), p. 9, n. ${ }^{\circ} 44-45$ y Pl. 17; cf. supra $\S$ 4.1.5, sobre otros sellos con la misma mención.

${ }^{87}$ Berrocal (1997), p. 122, lám. 1.7.

${ }^{88}$ Como sucede en nuestro sello, también los analizados por Cruishank Dodd (1961), Table III, n. ${ }^{\circ}$ 58-66, se valen del ángulo interior de ù para encajar el vértice del ángulo de la letra inferior (en nuestro caso A, en el de Dodd, Ä).
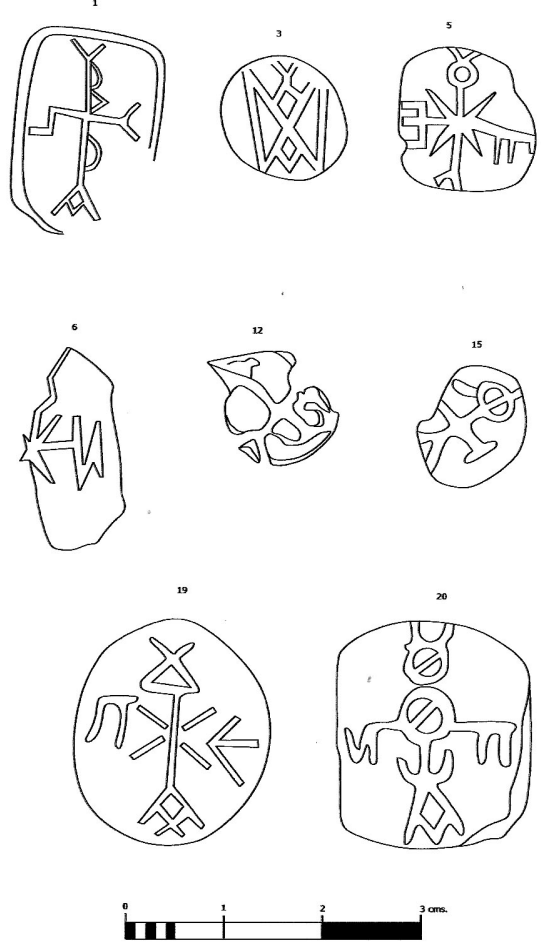

Fig. 8. Sellos documentados en los ungüentarios bizantinos de Cartagena. N. ${ }^{\circ} 1$ (CP 4203-178-1), 3 (CP 5234-178-1), 5 (CP 4567-178-1), 6 (CP 4868-178-1), 12 (CP 3416-178-1), 15 (CP 9265-178-1), 19 (B-03/1001-178-1), 20 (M-90/3-IIB)

que la confusión creada se puede superar en el caso de la ligadura -OY porque ésta es la forma esperable; en el caso del extremo izquierdo, porque la letra identificable ( $\mathrm{N}$ invertida) invalida la existencia de un trazo horizontal superior; en el centro de la cruz y en el brazo superior se distinguen dos letras de módulo redondo en las que, sin embargo, no es posible reconocer con certeza $\mathrm{O}, \Theta$ o $\Phi$.

Esta acumulación de letras es propia de monogramas tardíos, de finales del s. vi y primera mitad del s. vII. Se explica por la unión del nombre propio de un funcionario con su cargo ${ }^{89}$. En el caso de este sello, el nombre propio es probablemente Juan (I $\Omega A N-$ NOY), la explicación más plausible de la concatenación de las letras $\Omega$ A en el extremo inferior. En las restantes letras $(\Pi, \mathrm{O}, \Theta$ o $\Phi)$ habría que buscar el cargo de nuestro Juan: П en la posición en la que se encuentra en este sello suele formar parte de la indicación ЕПАРХОY (eparco), YПАТОY (cónsul) o ПАТРIKIOY (patricio), pero necesitaríamos que las

${ }^{89}$ Ejemplos de esta práctica en Wassiliou (2004), pp. 102103 (n. 78 y 79), ambos monogramas datables en el s. VII. 
restantes letras del brazo superior confirmaran esta hipótesis. En cualquiera de los tres casos hay abundantes funcionarios de nombre Juan atestiguados en los ss. VI y viI. Sólo uno de ellos es eparco de Constantinopla, en el s. $\mathrm{VI}^{90}$.

\section{CONCLUSIONES}

Creemos que el lote de piezas presentado se presta a ciertas conclusiones que pueden ser útiles en el estudio de este tipo de ungüentarios. Por lo que respecta a la cronología, a pesar de que algunas de las piezas integran estratos de datación amplia o se hallan claramente fuera de contexto, en su mayoría se datan entre la segunda mitad del siglo vi d.C. y el primer cuarto del siglo vi d.C.

Sin embargo, los estratos de dos piezas halladas en el teatro romano insinúan una datación ligeramente más temprana en el mismo siglo vi d.C. ${ }^{91}$ Nos referimos a aquellas encontradas en la etapa inmediatamente anterior a la construcción del barrio de época bizantina (CP 5234-178-1) o en el interior de una fosa cubierta por el relleno constructivo de una de las habitaciones de aquél (CP 6167-178-1), ejemplares que, no obstante, por lo menos en el primer caso, se acompañan de algunas formas cerámicas características de la segunda mitad de la sexta centuria, que hacen planear la duda acerca de un posible intrusismo. Por otro lado, también existe otro ungüentario cartagenero que quizá arribe a la ciudad en los prolegómenos del desembarco bizantino. Nos referimos a aquel (CP 4203-178-1) cuyo sello interpretamos como «de Gabrielio», y que, dada la frecuente alusión en estas piezas a la figura del eparco, quizá debamos identificar con el funcionario constantinopolitano que ocupa tal dignidad en el año 543.

La presencia de ejemplares en el barrio alicantino de Benalúa datados por el responsable de su estudio en un momento anterior al desembarco bizantino peninsular ofrece un caso paralelo de presencia de cerámica oriental en la primera mitad del s. $\mathrm{VI}^{92}$.

${ }^{90}$ Feissel (1986), p. 123 y n. 18 y Martindale (1992), p. 688 y Monogram n..$^{\circ} 167$; cf. Laurent (1952) n. 567, con un monograma similar, pero $\sin \Omega$ inferior y con $\mathrm{K}$ junto a la $\Pi$ derecha.

${ }^{91}$ Sobre el patrón de contactos regulares con Cartago anterior a la conquista bizantina, vid. Reynolds (1995), p. 122. Reynolds (ibidem, p. 133) es de la opinión de que los unguentaria llegarían a Occidente por una vía que no pasa por Cartago sino por Siracusa y el sur de Italia.

${ }^{92}$ Las excavaciones de este barrio alicantino son las intervenciones realizadas en Calle Churruca/Oscar Esplá/Calle Castelar y Avenida Oscar Esplá, donde se documentan sendos vertederos que, en ambos casos, parecen tener un límite
Respecto al momento final de circulación de los ungüentarios, hay que señalar su adscripción a conjuntos cerámicos posteriores al s. vi, como el de S. Polieucto en Estambul (Depósito 30) o el de Crypta Balbi en Roma, datable ca. 690. En el caso de Cartagena, los ungüentarios se hallan con relativa frecuencia en estratos de amplia cronología que abarcan hasta la etapa islámica (UU.EE 5301, 4868, 4847, 9265), cuando no en esta misma (UU.EE 4203, 4567) o incluso en alguna posterior (U.E 3416), lo que lleva a considerarlos integrantes del habitual porcentaje de residualidad ${ }^{93}$. Sin embargo, ello no resta verosimilitud a que algunos ungüentarios llegaran a la Península a comienzos del s. VII y así lo sugiere la presencia de algunos sellos con monogramas característicos de esa época, como el de M-90-3-IIb.

En definitiva, para nuestros ungüentarios, aceptando una comercialización genérica que parece arrancar en el siglo V para perdurar hasta el VII avanzado, en el caso hispano habría que circunscribirla sobre todo a la segunda mitad del siglo vi y primer cuarto de la siguiente centuria, horizonte en el que se localizan igualmente, aparte de las ya citadas piezas béticas de Málaga o Algeciras ${ }^{94}$, las de Barcelona $^{95}$ y Tarragona $^{96}$. De esta forma, si la impresión prelimi-

cronológico superior situado $\mathrm{ca}$. 575/580, y que, en el segundo caso, a pesar de abarcar materiales desde el siglo II, centra su período de actividad a partir del 500/525 con un tope superior en la mencionada fecha, pero con una intensidad mayor tan sólo hasta el 550. Cf. Reynolds (1993), pp. 53 y 578 , site 42.3 y 42.4 .

${ }^{93}$ Una pieza de fuera de Cartagena registrada en un momento posterior a la etapa bizantina es el ápice de ungüentario localizado en el Tolmo de Minateda, en el denominado horizonte IIIb, correspondiente a los materiales que aparecen en los niveles de abandono de casas islámicas y calles, que se fechan en época emiral, en concreto, hacia mediados del siglo IX; véase Gutiérrez, Gamo y Amorós (2003), pp. 148156, fig. 22.6. Con todo, la residualidad manifiesta hace considerar a los responsables de la excavación y estudio de los materiales una originaria pertenencia al horizonte I, en el que, no obstante, las producciones importadas son escasas y al parecer también residuales (ibidem, p. 138).

94 Sobre el contexto malacitano, cf. TIA (2000), pp. 273274. Para el ejemplar de Algeciras carente de sello y procedente de la Calle San Nicolás 1, tenemos constancia de su inclusión en un depósito con seguridad datado en la segunda mitad del siglo VI, donde, además, las formas de vajilla fina Hayes 99 o 104, los contenedores anfóricos (Keay LXI y Keay LIII) y aun el numerario, compuesto de pequeños num$m i$ entre los que hay uno justinianeo, permiten respaldar esa data (Navarro, Torremocha y Salado 2000, pp. 226-227). En cambio, no tenemos conocimiento de la cronología del yacimiento donde fue documentado el otro ungüentario de esta localidad gaditana, el de Calle Méndez Núñez, el que, a pesar de haber sido datado preliminarmente entre finales del siglo V y la siguiente centuria (Bernal 2003, p. 34), hoy día se considera, acorde con la mayoría de ejemplares, dentro de la segunda mitad de la sexta centuria. Agradecemos al profesor Bernal, de la Universidad de Cádiz, su información al respecto. 
nar fuera confirmándose con nuevos hallazgos, los ungüentarios que analizamos habrían llegado a España, salvo alguna excepción, únicamente tras la conquista bizantina del Mediodía hispano, a diferencia de otras mercancías orientales presentes previamente en cierta cantidad.

¿Significa esto que la llegada de LRU a la Península se vio favorecida por el aprovisionamiento que necesitaba la presencia bizantina en ella? Sin duda, la localización de ungüentarios orientales constituye una prueba más del comercio regular con el Mediterráneo oriental, en el que la intervención estatal está más que probada ${ }^{97}$; con todo, el beneficio económico explica igualmente la comercialización de productos orientales en Britania, Galia e Hispania ${ }^{98}$. La difusión de este tipo de envases en el Mediterráneo podría ser, pues, complementaria a la de los bienes de primera necesidad ${ }^{99}$ y respondería a una demanda prolongada en el tiempo, que quizá en un primer momento estimulada por las «colonias de comerciantes orientales» y favorecida por la presencia bizantina en el vecino norte de África ${ }^{100}$, sólo pudo ser satisfecha de modo adecuado una vez asentados los milites Romani en Hispania.

Por otra parte, que la administración imperial estaba implicada en la producción del contenido de estos ungüentarios es algo confirmado por la presencia - hemos visto dos ejemplos cartageneros - de sellos con la mención «del eparco» ${ }^{101}$. A pesar de las vacilaciones iniciales en la lectura de estas marcas, resulta muy verosímil que tal sea la resolución de los

${ }^{95}$ Beltrán de Heredia (2001), n. ${ }^{\circ} 295$.

${ }^{96}$ Bádenas de la Peña (2003), p. 146, n. ${ }^{\circ} 87$. Por lo demás, su lugar de aparición, presumiblemente la basílica de la necrópolis paleocristiana de Tarragona, experimenta un intenso uso funerario precisamente durante esas dos centurias, como anota Remolà (2000), pp. 100-101.

97 Gutiérrez Lloret (1998), pp. 166-167. Loseby (2005), pp. 615-617, quien (ibidem, p. 622) alude al tipo de comercio que atestiguan nuestros ungüentarios con la certera expresión de «luxury in nature, trivial in scale» y señala cómo habitualmente no es tenido en cuenta.

98 Dark (2003).

${ }^{99}$ Como sucede con el transporte de grandes ánforas orientales, acompañadas en el cargo por fina cerámica de mesa: Haldon (2005), pp. 35-38.

${ }^{100}$ Quizá a dicha demanda responde la presencia de nuestro ungüentario CP 4203-178-1, si el Gabrielio citado en su sello puede identificarse con el eparco constantinopolitano del 543. Lo cierto es que además de la frecuente alusión en estas piezas a la figura del eparco, también documentada en Cartagena, se trata en este caso de una fecha coherente con la expansión occidental justinianea, factores que vienen a apoyar la propuesta.

${ }^{101}$ A diferencia de otros materiales, en los sellos que marcan los ungüentarios no encontramos monogramas imperiales. En Iasos, sin embargo, algunos monogramas en caja se asemejan a los del emperador Mauricio: Baldoni y Franco (1995), p. 123, n. ${ }^{\circ} 6$. monogramas mencionados ${ }^{102}$, cuya presencia, en el caso de los objetos de plata, garantizaba la pureza del metal ${ }^{103}$, pero en el caso de los ungüentarios, sin duda, la calidad o cantidad del contenido, sobre el que sólo existen indicios de que se tratara de bálsamos ${ }^{104}$.

El control de este tipo de productos formaba parte de las atribuciones de uno de los altos funcionarios imperiales que llevaban ese término tan genérico de «eparco» ${ }^{105}$, que puede indicar cualquier persona que detenta el mando (en especial de una eparchia o provincia), pero que en lo relativo al control de las mercancías aludiría al prefecto de la Polis ${ }^{106}$. En el caso de los objetos de plata, y desde finales del reinado de Justiniano, es el prefecto de Constantinopla quien tenía la responsabilidad de garantizar con su sello la pureza del metal utilizado y la identificación del nombre de Gabrielio en uno de nuestros sellos apunta en el mismo sentido, puesto que tenemos noticia de un prefecto de Constantinopla llamado así1 ${ }^{107}$. Todas las interpretaciones de sellos con función similar se han decantado por identificar la autoridad implicada con este prefecto. Sin embargo, la

${ }^{102}$ La primera publicación de sellos de eparco es probablemente Schlumberger (1895), que recoge varios ejemplos en los que la inscripción «en tiempos del eparco $X »(\varepsilon \pi i \mathrm{X}$

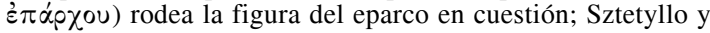
Borkowski (1985) publicaron un sello datable en el s. VII encontrado en el cuello de un ánfora con la formulación $\varepsilon \pi i$

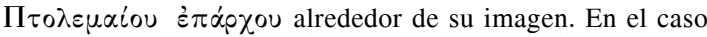
de los monogramas, no siempre se ha reconocido el cargo que esconden las letras EПА(P)XOY; cf. Metaxas (2005), pp. 83-84, n. ${ }^{\text {o }} 28$ y 29 [KatNr. 40 y 41; Taf. 2], pero lo lee

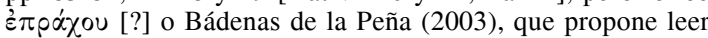
$\mathrm{A} \Pi(\mathrm{O} \Sigma \mathrm{TO}) \Lambda(\mathrm{OY}) \mathrm{XP}(\mathrm{I} \Sigma \mathrm{T}) \mathrm{OY}$.

${ }^{103}$ Cruishank Dodd (1961), p. 4; Mundell Mango (1992).

${ }^{104}$ Linke y Stanek (2005). Si la evidencia material es escasa, las hipótesis son abundantes. La más etérea es, sin duda, la de que contuvieran agua bendecida, aunque es más que dudoso que el Estado pusiera medios en el control de la calidad/cantidad de ese producto. Por fortuna, en algunos ejemplares encontrados en Siracusa, se ha observado la presencia de una especie de pez que sugeriría que el producto contenido fuera óleo sagrado; cf. el trabajo de B. Pace, Arte e civiltà della Sicilia antica, IV, Roma 1949, p. 444, cit. por Baldoni y Franco (1995), p. 121.

105 Sobre las funciones del eparco en la Antigüedad tardía, véase en especial los trabajos de Feissel (1986) y (1991); cf. Kazhdan et al. (1991), pp. 704-705, s. v. Eparch, Eparch of the City; H. Ahrweiler (1961), R. Guilland (1980), (1981), (1982), J.-Cl. Cheynet (1984) y E. Papagianni (2002).

${ }^{106}$ Nuestra información sobre las atribuciones del prefectus Urbis procede principalmente de un testimonio posterior, el Libro del Eparco, que presenta la forma de un edicto imperial atribuido a León VI (ed. J. Koder [1991]) y -mencionémoslo como curiosidad- regula la actividad de los vendedores de ungüentos (X, De unguentariis, 1-6). Igualmente, cf. el interesante Daniele (2006). Sabemos que su sello o bulla se aplicaba como garantía en las medidas, balanzas y pesas de los mercaderes o las telas destinadas a la exportación.

${ }^{107}$ Feissel (1986), p. 120. 
producción de ungüentarios protobizantinos no es constantinopolitana, sino anatolia, y el prefectus Urbis no tendría ninguna jurisdicción sobre ella, al contrario que el prefectus Orientis, la primera figura administrativa de Anatolia, que bien podría haber puesto un marchamo homologador en el prestigioso producto que contenían los recipientes. Una posible explicación es que el interés (quizá fiscal) de la administración central en el control del producto llevara a que el prefecto enviara su estampilla al centro minorasiático y un delegado suyo controlara el llenado de los recipientes ${ }^{108}$.

Sea como fuere, la presencia de estos «monogramas secundarios» de funcionarios imperiales y, en concreto, del eparco, pero también (hipotéticamente) de un hypatos o cónsul, no es incompatible con la existencia de ungüentarios sellados por miembros de la administración eclesiástica ${ }^{109}$. Como es sabido, en Rodas vio la luz un ungüentario con el sello de un obispo de nombre Severiano y en Iasos otro similar de un obispo Erasino ${ }^{110}$; pero también parece haberse identificado en los sellos algún miembro del clero, como el anagnostes mencionado en una pieza de Éfeso ${ }^{111}$. Sin duda, los nombres propios que esconden muchos monogramas responden a una $u$ otra categoría de funcionario imperial o eclesiástico. En una realidad como la que se vivía en Anatolia en ese largo final del mundo antiguo, no es sorprendente que la administración eclesiástica se hiciera cargo del control de la producción, en fases intermitentes o en la etapa final, y se beneficiara de ello.

Algunos estudiosos están persuadidos del valor religioso del contenido de los unguentaria y de un uso en contextos de culto cristiano heredero de la función de este tipo de recipientes en los ritos de enterramiento de época helenística y romana ${ }^{112}$. Una pervivencia de este ritual explicaría, de hecho, la presencia de un LRU en la necrópolis paleocristiana de Tarragona, quizás dentro de una de las tumbas que ocupan el espacio de la basílica ${ }^{113}$. Algunas con-

\footnotetext{
${ }^{108}$ En apoyo de esta hipótesis viene la existencia y uso en Egipto de pesos de vidrio que se utilizaban para pesar monedas en el s. VI y que llevan el nombre del emperador o del eparco de Constantinopla; véase Schlumberger (1895), 5862.

${ }^{109}$ Baldoni y Franco (1995), p. 123, n. ${ }^{\circ} 2$.

110 El primero citado por Grünbart-Lochner-Metaxas (2004), 182 y Abb. 2; el segundo, publicado en Baldoni y Franco (1995), 121 y 126, n. ${ }^{\circ} 29$.

${ }^{111}$ Lochner et al. (2005), p. 649, n. ${ }^{\circ} 36$

${ }^{112}$ Anderson-Stojanovic (1987). La falta de funcionalidad de estas vasijas está demostrada por el hecho de que, en algunos casos, la boca de los ungüentarios esté cerrada con arcilla y, en otros, de que la porosidad de la arcilla impida el almacenamiento de cualquier líquido.

113 Remolà (2000), n. 179.
}

tribuciones proponen, así, vincular la producción de LRU a la distribución de óleo santificado por San Nicolás de Mira o Santa Tecla en Seleucia, cuyo culto disfrutaba de una compleja organización altamente ventajosa para la economía de sus respectivas comarcas $^{114}$. No obstante, el hecho de que en estas mismas regiones se manufacturen ampollas de peregrino que quizá monopolicen estos usos, cuestiona esas propuestas $^{115}$.

En la misma dirección, contra la vinculación exclusiva al culto de estos envases se impone el dato de que, a diferencia de las referidas ampullae, no se conocen ungüentarios marcados con las invocaciones tan comunes a la Virgen o Jesucristo ni con los símbolos cristianos más difundidos: la cruz (con una excepción ${ }^{116}$ ), el crismón (XP) o la imagen de un cordero; por el contrario, sí encontramos otros animales, como el león o el escorpión, en este caso en un contexto de motivos gnósticos ${ }^{117}$. Si, por lo tanto, la única prueba de la implicación de la Iglesia en la producción de ungüentarios es la presencia de sellos de obispos, deducir de ello la vinculación de su contenido con el culto cristiano o las prácticas religiosas es muy arriesgado. Supone olvidar que uno de los rasgos definitorios de la Antigüedad tardía es la transferencia de poder del Estado a la Iglesia y la asunción por parte de los obispos de responsabilidades políticas y económicas como cabezas de su comunidad y defensores de su grey ${ }^{118}$.

Por otra parte, tampoco prueba un uso religioso de los ungüentarios su localización en recintos monásticos como los de Saraçhane, Crypta Balbi o el «Palacio de los Gigantes» del ágora de Atenas ${ }^{119} \mathrm{o}$, en Hispania, en Punta de L'Illa de Cullera ${ }^{120}$, así como en las zonas episcopales ya aludidas de Valencia o Barcelona. Los monasterios y las sedes de la admi-

114 Sobre S. Nicolás de Mira, Sodini (2001); cf. Koenig (1982) 109. En cuanto al significado de la feria de Santa Tecla, Dagron (1978); Whittow (1990), pp. 21-23.

${ }_{115}$ Arias Sánchez y Novoa Portela (1999) y (2003).

116 Metaxas (2005), p. 87, n. ${ }^{\circ} 42$.

${ }^{117}$ Hayes (1992), p. 9, n. ${ }^{\circ} 51$.

118 Pérez Martín (2003), pp. 242-243. La vinculación de los obispos en la comercialización de los envases es un fenómeno extendido que encontramos en el caso del vino producido en el área del Estrecho de Mesina, transportado en las ánforas tipo Keay LII (Saguì [2001], p. 289), en las ánforas egipcias LRA 7 -donde es frecuente encontrar tituli picti o estampillas que, entre otras posibilidades, hacen referencia a dominios eclesiásticos- o en la popular LRA 1 / Keay LIII (estampillado con cruz patada) como el ánfora de Aqaba, en la que también se registra alguna pieza con titulus pictus de monograma similar al de nuestros ungüentarios, junto a cruces, evidencias todas que llevan a preguntarse acerca de la existencia de talleres eclesiásticos. Véase Pieri (2007), fig. 3.

${ }^{119}$ Frantz (1988), p. 91, Tab. 73b.

${ }^{120}$ García y Rosselló (1993), p. 299. 
nistración eclesiástica no eran solamente lugares donde se praticaba el culto cristiano, eran también centros económicos, en ocasiones extremadamente activos, y servían de residencia a una élite socioeconómica para la que el contenido de los LRU debía de ser en el s. VI un producto de uso común. Del mismo modo, la presencia de ungüentarios en lugares sin función religiosa alguna, como Hierápolis, Algeciras, Málaga o Cartagena, no impide un uso religioso privado. Hemos de recordar que, en especial, estos dos últimos casos nos muestran una presencia abultada de este tipo de piezas.

Si la presencia de sellos de la administración imperial no previene su contenido de ser de uso cultual, tampoco la presencia de sellos obispales es óbice para que el contenido no tenga que ver con la religión. No es descartable, así, que los LRU sirviesen simplemente para la comercialización de productos de lujo, como aceites perfumados o ungüentos ${ }^{121}$. De la misma forma, también se ha señalado la posibilidad de que contuvieran salsas especiales o vinos preciados, entre otras opciones ${ }^{122}$. La hipótesis de que contuvieran productos de lujo en pequeñas cantidades como dichos ungüentos, de elevado coste y por ello destinados a las capas sociales de mayor poder adquisitivo, choca con su amplia documentación en contextos domésticos de poblaciones como Carthago Spartaria, sin duda desahogados, a juzgar por un rico ajuar cerámico importado, pero tampoco privilegiados, como evidencian todas sus características constructivas ${ }^{123}$. Hemos de tener en cuenta a este respecto, que, además, el caso de la ciudad hispana no es ninguna excepción, pues similar resulta también el de los ejemplares lunenses, recuperados igualmente en estratos pertenecientes a las casas lígneas construidas sobre el foro o también el de las numerosas piezas localizadas en la Casa de los Capiteles Jónicos de Hierápolis ${ }^{124}$. En este sentido, ya el mismo Hayes señaló desde un principio la existencia de este tipo de recipientes en las casas, quizá conteniendo óleo bendecido usado con fines medicinales $^{125}$.

121 Saguì (1998), p. 311. No en vano Isidoro de Sevilla señala el papel tradicional de Oriente en la comercialización de estos productos; cf. Etym. XIV,3,10: En esta región [sc. Asiria], por primera vez, se descubrió el uso de la púrpura, y de ella vinieron los ungüentos y perfumes para los cabellos y el cuerpo, con los que más tarde nació la vana suntuosidad de romanos y griegos.

${ }^{122}$ Lusuardi y Murialdo (1991), p. 123. Señalando contenidos alternativos, cf. también Koenig (1982), p. 45.

${ }^{123}$ Bernal y Vallejo (2003), p. 132.

${ }^{124}$ Lusuardi y Murialdo (1991), pp. 123-124, tav. 1, 1-3, y Cottica (1998), pp. 81-90.

${ }^{125}$ Hayes (1971), p. 247, n. 19.

\section{BIBLIOGRAFÍA}

M. Acién, J. N. Castaño, I. Navarro, J. B. Salado Y M. VerA (2003): «Cerámicas tardorromanas y altomedievales en Málaga, Ronda y Morón», Cerámicas tardorromanas y altomedievales en la Península Ibérica», L. Caballero, P. Mateos y M. Retuerce eds., Madrid (Anejos de Archivo Español de Arqueología 28), pp. 411-454.

H. Ahrweiler (1961): «Fonctionnaires et bureaux maritimes à Byzance», Revue des Études Byzantines, 19, pp. 239-252 [= Études sur les estructures administratives et sociales de Byzance, London 1971 (Variorum Reprints), XI].

V. R. ANDERSON-StOJANOviC (1987): «The Chronology and Function of Ceramic Unguentaria», AJA 91, pp. 105-122.

I. Arias Sánchez y F. Novoa Portela (1999): «Ampullae: ampollas de peregrino en el Museo Arqueológico Nacional», Boletín del Museo Arqueológico Nacional 17, pp. 141-174.

- (2003): «Ampolla de Peregrino», Bizancio en España. De la Antigüedad tardía a El Greco, Catálogo de la Exposición, Madrid, p. 233.

P. BÁdenAs de la PeÑa (2003): «Monograma bizantino», Bizancio en España. De la Antigüedad tardía a El Greco, Catálogo de la Exposición, Madrid, n. ${ }^{\circ}$ 92, pp. 152-153.

D. Baldoni y C. Franco (1995): «Unguentaria tardo antichi da Iasos», Rivista di Archeologia 19, pp. 121-128.

D. BALDONI (1999): «Unguentaria tardoantichi da Iasos: Addendum», Quaderni Friulani di Archeologia 9, pp. 131-135.

J. BARDILl (2004): Brickstamps of Constantinople, I, Text, Oxford (Oxford Monographs on classical Archaeology).

J. Beltrán de Heredia (2001): De Barcino a Barcinona. Los restos arqueológicos de la Plaza del Rey de Barcelona, Barcelona.

D. Bernal (2003): «Ungüentario tardorromano de importación oriental», Algeciras Andalusí (siglos VIII-XIV), Catálogo de la Exposición, Fundación Municipal de Cultura Jose Luis Cano, Algeciras, 3 de julio al 31 de diciembre de 2003, Algeciras, p. 34.

D. Bernal y M. Vallejo (2003): «Vida cotidiana en Bizancio», Bizancio en España. De la Antigüedad tardía a El Greco, Catálogo de la Exposición, Madrid, pp. 128-135.

M. ${ }^{a}$ C. Berrocal, «Late Roman Unguentarium en Carthago-Noua», Actas del XXIII Congreso Nacional de Arqueología: Elche 1995, Elche 1997, pp. 119-128. 
J.-Cl. Cheynet (1984): «L'Éparque: correctifs et additifs», en Byzantinoslavica 45, pp. 50-54.

J. C. Cheynet, C. Morrisson y W. Seibt (1991): Sceaux Byzantins de la Collection Henri Seyrig. Catalogue Raisonné, Paris.

J.-C. Cheynet (1994): «Sceaux d'Antioche et de Tarse», Travaux et Mémoires 12, pp. 391-478.

M. Clarc y G. A. D’Agnel (1904): Découvertes archéologiques à Marseille, Marseille.

J. Coll (1997): «Cerámica y evolución del patrón de asentamiento en el Valle de Soller (Mallorca, Baleares) (siglos IV al XII), Actas del XXIII Congreso Nacional de Arqueología: Elche 1995, Elche, pp. 395-420.

D. Cotтica (1998): «Ceramiche bizantine dipinte ed unguentari tardo antichi dalla «Casa dei Capite1li Ionici» a Hierapolis», Rivista di Archeologia 22, pp. 81-90.

D. Cotтica (2000): «Unguentari tardo antichi dal Martyrion di Hierapolis, Turchia», Mélanges de l'École Française de Rome. Antiquité 112.2, pp. 999-1021.

D. Cruishank Dodd (1961): Byzantine Silver Stamps, Washington.

G. Dagron (1978): Vie et miracles de Sainte Thècle (Subsidia Hagiographica 62), Bruxelles.

L. Daniele (2006): «Brevi note introduttive circa l'Eparchikon Biblion (Libro dell'eparca) quale prodromo di un "Code du Commerce" nell'Impero Romano d'Oriente», Iura Orientalia 2, pp. 13-26.

K. DARK (2003): «Early Byzantine Mercantile Communities in the West», en C. Entwistle ed., Through a Glass Brightly: Studies in Byzantine and Medieval Art and Archaeology Presented to David Buckton, Oxford, pp. 76-81.

U. EISENMENGER y A. ZÄH (1999): «Ampullae tardoantiche dell'Asia Minore. Nuovi esempi da Cnido e Limyra», Quaderni Friulani di Archeologia 9, pp. 113-130.

D. Feissel (1986): «Le préfet de Constantinople, les poids-étalons et l'estampillage de l'argenterie au VIe et au VIIe siècle», Revue Numismatique 28, pp. 119-142.

- (1991): «Praefatio Chartarum Publicarum. L'intitulé des actes de la préfecture du prétoire du IVe au VIe siècle», TM 11, pp. 437-464.

W. FINK (1981): «Das Frühbyzantinische Monogramm. Untersuchungen zu Lösungsmöglichkeiten», Jahrbuch der Österreichischen Byzantinistik 30, pp. 75-86.

J. FonTAine (2000): «Un général byzantin en Espagne en 589: Observations sur la romanité de l'Inscription byzantine de Carthagène (Vives
362)», Romanité et cité chrétienne. Permanences et mutations. Intégration et exclusion du Ie au VIe siècle, Paris, pp. 91-100.

A. Frantz (1988): The Athenian Agora XXIV. Late Antiquity: A.D.267-700, Princeton.

M. G. Fulford y D. PS. PEACock (1984): Excavations at Carthage: The British Mission, I, 2, The Avenue du President Habib Bourguiba, Salammbo. The pottery and other ceramic objects from the site, Sheffield.

M. ' J. García y M. Rosselló (1993): «Late Roman Unguentarium: Ungüentarios cristianos de la Antigüedad Tardía procedentes de Punta de L'Illa de Cullera, Valencia», Archivo Español de Arqueología 66, pp. 294-300.

M. Grünbart y S. Lochner-Metaxas (2004): «Stempel(n) in Byzanz», Wiener Byzantinistik und Neogräzistik. Beiträge zum Symposion vierzig Jahre Institut für Byzantinistik und Neogräzistik der Universität Wien im Gedenken an Herbert Hunger (Wien, 4.-7. Dezember 2002), W. Hörandner, J. Koder y M. A. Stassinopoulou eds., Wien, pp. 177-189.

R. Guilland (1980-82): «Études d'histoire administrative de 1'Empire byzantin, L'éparque», Byzantinoslavica 41, pp. 17-32 y 165-180; ibid. 42 (1981), pp. 186-196; ibid. 43 (1982), pp. 30-44.

M. M. GumÀ, M. Riera y F. Torres (1997): «Contextos ceràmics dels segles IV-X a l'illa de Mallorca», Arqueo Mediterrània 2, pp. 249-264.

S. Gutiérrez Lloret (1998): «Eastern Spain in the Sixth Century», The Sixth Century: Production, Distribution and Demand, R. Hodges y William Bowden eds., Leiden [etc.]: Brill, pp. 161-184.

S. Gutiérrez, B. Gamo y V. Amorós (2003): «Los contextos cerámicos altomedievales del Tolmo de Minateda y la cerámica altomedieval en el sureste de la Península Ibérica», Cerámicas tardorromanas y altomedievales en la Península Ibérica, L. Caballero, P. Mateos y M. Retuerce eds., Madrid (Anejos de Archivo Español de Arqueología 28), pp. 119-168.

J. HAldon (2005): «Economy and Administration: how did the Empire work», The Cambridge Companion to the age of Justinian, M. Maas ed., Cambridge, pp. 28-59.

R. M. HARRISON (1986): Excavations at Saraçhane in Istanbul, I, The Excavations, Structures, Architectural Decoration, Small Finds, Coins, Bones and Molluscs, Princeton.

J. W. Hayes (1971): «A New Type of Early Christian Ampulla», BSA 66, pp. 243-248.

- (1972): Late Roman Pottery, London. 
- (1992): Excavations at Saraçhane in Istambul, II, The Pottery, Princeton.

- (2001): «Late Roman Fine wares and their Successors: A Mediterranean Byzantine Perspective (with Reference to the Syro-Jordanian Situation», La céramique byzantine et proto-islamique en Syrie-Jordanie (IVe - VIIIe siècles apr. J.-C.). Actes du colloque tenu à Amman les 3, 4 et 5 décembre 1994, E. Villeneuve-P. M. Watson eds., Beyrouth: Institut Français d'Archéologie du Proche-Orient, pp. 275-282.

A. KaZHDAn et al. (1991): The Oxford Dictionary of Byzantium, New York-Oxford, 3 vols.

S. KeAY (1984): Late Roman Amphorae in the Western Mediterranean. A tipology and Economic Study: the Catalan Evidence, Oxford (BAR International Series 196), 2 vols.

J. Koder (1991): Das Eparchenbuch Leons des Wesen. Einführung, Edition, Übersetzung und Indices, Wien (Corpus Fontium Historiae Byzantinae 23, Series Vindobonensis).

G. G. Koenig (1982): «Schamane und Schmeid, Medicus und Mönch: Ein Überblick zur Archäologie der merowingerzeitlichen Medizin im südlichen Mitteleuropa», en Helvetia archaeologica $13, \mathrm{n}^{\circ}$ 51-52, pp. 75-154.

E. LAFLÝ (2005): «Spätantik-Frühbyzantinische Tounguentarien aus Seleukeia Sidera in Pisidien (Südwesttürkei)», $1^{\text {st }}$ International Conference on Late Roman Coarse Wares, Cooking Wares and amphorae in the Mediterranean: Archaeology and Archaeometry (Barcelona, 14-16 March 2002), J. M. ${ }^{a}$ Gurt i Esparraguera, J. Buxeda i Garrigós y M. A. Cau Ontiveros eds., Oxford (BAR International Series 1340), pp. 667-679.

- (2005bis): «Erster vorläufiger Bericht über die Römish-Kaiserzeitlichen und Spätantiken Keramikfunde aus Antiocheia in Pisidien: Spätantikfrühbyzantinischen Tonunguentarien», en Y. Hazirlayanlar, 22. Arastirma Sonuçlari Toplantisi 2. Cilt, Kültur Varlýklarý ve Müzeler Genel Müdürlügü, 107, Ankara, pp. 175-188.

M. ${ }^{a}$ D. Laíz y E. Ruiz (1988): «Cerámicas de cocina de los siglos v-VII en Cartagena (C/Orcel-Don Gil)», en Antigüedad y Cristianismo 5, pp. 265301.

V. LAurent (1952): Documents de Sigillographie. La Collection C. Orghidan, Bibliothèque Byzantine, Paris.

R. Linke y S. StaneK (2005): «Materialanalytische Untersuchungen von Rückständen an «ephesischen» frühbyzantinischen Amphoriskoi», en Spätantike und mittelalterliche Keramik aus Ephe- sos, herausgegeben von F. Krinzinger, Wien (Österreichische Akademie der Wissenschaften. Archäologische Forschungen, 13), pp. 137-142.

S. Lochner, R. SAuer y R. Linke (2005): «Late Roman Unguentaria? A contribution to Early Byzantine wares from the view of Ephesus», $1^{\text {st }}$ International Conference on Late Roman Coarse Wares, Cooking Wares ana amphorae in the Mediterranean: Archaeology and Archaeometry

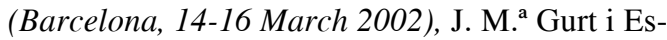
parraguera, J. Buxeda i Garrigós y M. A. Cau Ontiveros eds., Oxford (BAR International Series 1340), pp. 647-654.

S. T. Loseby (2005): Chap. 22. The Mediterranean economy, The New Cambridge Medieval History, vol. 1, c. 500-c. 700, P. Fouracre ed., Cambridge, pp. 605-638.

S. Lusuardi y G. Murialdo (1991): «Le ceramiche mediterranee in Liguria durante il periodo bizantino (VI-VII secolo)», A Cerâmica Medieval no Meditarrâneo occidental (Lisboa, novembro 1987), Lisboa, pp. 123-146.

M. Mackensen (1998): «Centres of African red slip ware production in Tunisia from the late 5 th to the 7th century», Ceramica in Italia: VI-VII secolo. Atti del Convegno in onore di John W. Hayes. Roma, 11-13 maggio 1995, a cura di L. Saguì, I, Firenze, pp. 23-39.

M. ${ }^{a}$ J. MAdRid y J. Vizcaíno (2006): «La necrópolis tardoantigua del sector oriental de Cartagena», Espacios y usos funerarios en la ciudad histórica. VI Jornadas de Arqueología Andaluza, Córdoba (Anales de Arqueología Cordobesa 2), pp. 195-224.

- (2006bis): «Nuevos elementos de ajuar de la necrópolis oriental de Carthago Spartaria (I)», Mastia 5, pp. 85-130.

- (2007): «Nuevos elementos de ajuar de la necrópolis oriental de Carthago Spartaria (II)», en Mastia 6, pp. 37-90.

- (2008): «Collares de época bizantina procedentes de la necrópolis oriental de Carthago Spartaria», Verdolay 12 [en prensa].

F. Marazzi (2001): «Sigilli dai depositi di VII e VIII secolo dell'esedra della Crypta Balbi», Roma. Dall'Antichità al Medioevo. Archeologia e Storia nel Museo Nazionale Romano Crypta Balbi, a cura di M. S. Arena et al., Milano, pp. 257-259.

O. Marlasca (2001): «Quelques points de droit commercial et maritime dans la Lex Visigothorum», Revue internationale des droits de l'Antiquité 48, pp. 213-235.

J. R. Martindale (1992): The Prosopography of the 
Later Roman Empire, III, AD 527-641, Cambridge: The University Press.

S. Metaxas (2005): «Frühbyzantinische Ampullen und Amphoriskoi aus Ephesos», Spätantike und mittelalterliche Keramik aus Ephesos, herausgegeben von F. Krinzinger, Wien (Österreichische Akademie der Wissenschaften. Archäologische Forschungen 13), pp. 67-124.

V. Mitsopoulos-Leon (1991): Die Basilika am Staatsmarkt in Ephesos. Kleinfunde, I, Keramik hellenisticher und römischer Zeit, Wien (Forschungen in Ephesos IX 2/2).

M. Mundell Mango (1992): «Purpose and Places of Silver Stamping», Ecclesiastical silver plate in sixth-century Byzantium. Papers of the Symposium held May 16-18, 1986 at the Walters Art Gallery, Baltimore and Dumbarton Oaks, S. A. Boyd y M. Mundell Mango eds., Washington DC, Dumbarton Oaks Research Library and Collection, pp. 203-215.

A. J. Murcia (2000): «Asentamientos rurales de los siglos V-VII d.C en el contorno de Cartagena», $V$ Reunió d'Arqueologia Cristiana Hispànica (Cartagena 1998), Barcelona, pp. 371-382.

A. J. Murcia y M. Guillermo (2003): «Cerámicas tardorromanas y altomedievales procedentes del Teatro Romano de Cartagena», Cerámicas tardorromanas y altomedievales en la Península Ibérica, L. Caballero, P. Mateos y M. Retuerce eds., Madrid (Anejos de Archivo Español de Arqueología 28), pp. 202-209.

A. J. Murcia (2005): «Materiales pertenecientes a los ajuares domésticos altoimperiales de Carthago Noua: los hallazgos de la calle Beatas», Verdolay 9, pp. 177-194.

G. Murialdo (2001): «I rapporti economici con l'area mediterranea e padana», S. Antonino: un insediamento fortificato nella Liguria bizantina, a cura di T. Mannoni y G. Murialdo, Bordighera, pp. 302-303.

I. Navarro, A. Torremocha y J. B. Salado (2000): «Primeros testimonios arqueológicos sobre Algeciras en época bizantina», V Reunió d'Arqueologia Cristiana Hispànica (Cartagena 1998), Barcelona, pp. 223-228.

M. Paganelli (2001): «Late roman Unguentarium», en Roma dall'Antichità al Medioevo. Archeologia e Storia nel Museo Nazionale Romano Crypta Balbi, Milano.

E. Papagianni (2002): «Byzantine Legislation on Economic Activity Relative to Social Class», Economic History of Byzantium, ed. by A. Laiou, Washington, pp. 1083-1094.
P. Pascual, A. Ribera, M. Roselló y T. Marot (1997): «València i el seu territori: contexts ceràmics de la fi de la Romanitat a la fi del califat (270-1031)», Contextos ceràmics d'època romana tardana $i$ de l'alta edat mitjana (segles $I V-X$ ), Arqueo Mediterrània 2, pp. 179-202.

C. Perassi (2002): «Pesi monetali bizantini in vetro dal territorio siciliano», Atti del I Congresso internazionale di archeologia della Sicilia bizantina, (Corleone, 28 luglio-2 agosto 1998), Palermo (Byzantino-Sicula 4), pp. 439-474.

I. Pérez Martín (2003): «Bizancio y sus ciudades», De la aldea al burgo: La ciudad como estructura urbana y política en el Mediterráneo, A. Pérez Jiménez y G. Cruz Andreotti eds., Málaga (Mediterranea 11), pp. 225-282.

D. PIERI (2007): «Les centres de production d'amphores en Mediterranée Orientale durant 1'Antiquité Tardive: Quelques Remarques», Late Roman Coarse Wares, Cooking Wares and Amphorae in the Mediterranean. Archaeology and archaeometry, M. Bonifay y J.-Chr. Tréglia eds., Oxford (BAR International Series 1662), II, pp. 611-626.

A. PREgo DE LIS (1999): «Nueva lectura de la inscripción de «Comenciolo» del Museo Municipal de Arqueología de Cartagena», XXIV Congreso $\mathrm{Na}$ cional de Arqueología, Cartagena 1997, Murcia, pp. 31-38.

A. Prego de Lis (2000): «La inscripción de Comitiolus del Museo Municipal de Arqueología de Cartagena», V Reunió d'Arqueologia Cristiana Hispànica (Cartagena 1998), Barcelona, pp. 383-392.

S. F. Ramallo, E. Ruiz y M. ${ }^{a}$ C. Berrocal (1996): «Contextos cerámicos de los siglos v-VII en Cartagena», Archivo Español de Arqueología 69, pp. 135-190.

S. F. Ramallo, E. Ruiz y M. a C. Berrocal (1997): «Un contexto cerámico del primer cuarto del siglo vil en Cartagena», Arqueo Mediterrània 2, pp. 203-228.

S. F. Ramallo y J. Vizcaíno (2002): «Bizantinos en Hispania. Un problema recurrente en la arqueología española», Archivo Español de Arqueología 75, pp. 313-332.

S. F. Ramallo y J. Vizcaíno (2003): «Cartagena en época de San Isidoro a través de la evidencia arqueológica», San Isidoro, Doctor de las Españas, Sevilla, pp. 43-74.

S. F. Ramallo y J. Vizcaíno (2007): «Evolución del sistema defensivo de Cartagena durante la Antigüedad», Murallas de Ciudades Romanas en el Occidente del Impero. Lucus Augusti como para- 
digma, Actas del Congreso Internacional celebrado en Lugo (26-29, XI. 2005) en el V aniversario de la declaración, por la UNESCO, de la Muralla de Lugo como Patrimonio de la Humanidad, Lugo, pp. 483-522.

J.A. Remolà (2000): Las ánforas tardo-antiguas en Tarraco (Hispania tarraconensis). Siglos IV-VII d.C, Barcelona.

P. Reynolds (1993): Settlement and Pottery in the Vinalopó Valley (Alicante, Spain). A.D. 400-700, Oxford (BAR International Series 588).

- (1995): Trade in the western Mediterranean, AD 400-700. The ceramic evidence, Oxford (BAR international series 604).

- (2003): Spain, Portugal and the Balearics: 4th7th century (Late Roman, Byzantine and Visigothic), en VIIe Congrès International sur la Céramique Médiévale en Méditerranée, Thessaloniki, 11-16 Octobre 1999. Actes, Athina, pp. 571-585.

J. A. RILEY (1975): «The pottery from the first session of excavation in Caesarea Hippodrome», Bulletin of the American School of Oriental Research 218, pp. 31-50.

- (1979): «The Coarse Pottery from Berenice», Excavations at Sidi Khrebish Benghazi (Berenice), J. A. Lloyd ed., Tripoli (Supplements to Libya Antiqua V, 2), pp. 91-467.

H. Robinson (1959): The Athenian Agora, V: Pottery of the Roman Period: Chronology, Princeton.

M. Roselló, A. Ribera y J. Pascual (2003): «Cerámicas de la ciudad de Valencia entre la época visigoda y omeya (siglos VI-X)», Cerámicas tardoromanas y altomedievales en la Península Ibérica, L. Caballero, P. Mateos y M. Retuerce eds., Madrid (Anejos de Archivo Español de Arqueología 28), pp. 67-118.

M. Roselló (2005): «El territorium de Valentia en 1'Antiguitat Tardana», VI Reunió d'Arqueologia Cristiana Hispànica (València, 2003), Barcelona, pp. 279-304.

G. Ripoll y J. M. GuRT, eds. (2000): Sedes regiae (ann. 400-800), Barcelona.

L. SAGUì (1998): «Il deposito della Crypta Balbi: una testimonianza imprevidibile sulla Roma del VII secolo», Ceramica in Italia: VI-VII secolo. Atti del Convegno in onore di John W. Hayes. Roma, 1113 maggio 1995, a cura di L. Saguì, I, Firenze, pp. 305-330.

- (2001): «Anfore», Roma dall'Antichità al Medioevo. Archeologia e Storia nel Museo Nazionale Romano Crypta Balbi, Milano, p. 289.

M. ${ }^{a}$ D. SÁnchez de Prado (1999): «Acerca del vidrio romano de Cartagena», XXIV Congreso Nacional de Arqueología [celebrado] en Cartagena 1997, Cartagena, pp. 125-136.

R. Sauer y S. Ladstätter (2005): «Mineralogischpetrographische Analysen von frühbyzantinischen Ampullen und Amphoriskoi aus Ephesos», Spätantike und mittelalterliche Keramik aus Ephesos, herausgegeben von F. Krinzinger, Wien (Österreichische Akademie der Wissenschaften. Archäologische Forschungen, 13), pp. 125-136.

G. Schlumberger (1895): «Poids de verre étalons monétiformes d'origine byzantine», $R E G 8$, pp. 5976.

J. SERra (1929): Excavaciones en la necrópolis romano-cristiana de Tarragona, Madrid (Junta Superior de Excavaciones y Antigüedades, 104).

J. P. Sodini (2001): Prologue a La céramique byzantine et proto-islamique en Syrie-Jordanie (IVe VIIIe siècles apr. J.-C.). Actes du colloque tenu à Amman les 3, 4 et 5 décembre 1994, E. Villeneuve-P. M. Watson eds., Beyrouth: Institut Français d'Archéologie du Proche-Orient.

Z. SzTETYLlo y Z. Borkowski (1985): «Un timbre céramique byzantin de l'éparque de Constantinople», Recherches sur les amphores grecques $(\mathrm{Bu}-$ lletin de Correspondance Hellénique, Supplément 13), Y. Empereur-Y. Garlan eds., Athènes, pp. 649-654.

Taller de Investigaciones Arqueológicas [TIA] (2000): «Malaca bizantina: primeros datos arqueológicos», V Reunió d'Arqueologia Cristiana Hispànica : Cartagena, 16-19 d'abril de $1998=$ VReunión de Arqueología Cristiana Hispánica: Cartagena, 16-19 de abril 1998, Barcelona, pp. 271-278

TIA (2001): «Comercio y comerciantes en la Málaga bizantina», Comercio y comerciantes en la Historia Antigua de Málaga (Siglo VIII a.Caño 711 d.C), en II Congreso de Historia Antigua de Málaga, F. Wulff Alonso, G. Cruz Andreotti y C. Martínez Maza eds., Málaga, pp. 681698.

S. Tortorella (1998): «La sigillata africana in Italia nel VI e VII secolo d.C: problema di cronologia e distribuzione», Ceramica in Italia: VI-VII secolo. Atti del Convegno in onore di John W. Hayes. Roma, 11-13 maggio 1995, a cura di L. Saguì, I, Firenze, I, pp. 41-68.

I. Touratsoglou, I. Koltsida y Y. Nikolaou (2006): «New Lead Seals from Crete», Studies in Byzantine Sigillography 9, pp. 49-68.

A. UsCatescu (1996): La cerámica del macellum de Gerasa (Yareis, Jordania), Madrid.

M. Vallejo (1993): Bizancio y la España Tardoan- 
tigua (ss. V-VIII): Un capítulo de historia mediterránea, Alcalá de Henares.

J. VizCAÍNO (1999): «Transformaciones del urbanismo tardoantiguo en Cartagena. El caso de los vertederos», Anales de Prehistoria y Arqueología de la Universidad de Murcia 15, pp. 87-98.

- (2005): «Heterogeneidad cultural en la ciudad tardoantigua a través del registro material: El cuerno de vidrio procedente de Cartagena en época bizantina», VI Reunió d'Arqueologia Cristiana Hispànica (València, 2003), Barcelona, pp. 391-398.

J. Vizcaíno y M. ${ }^{a}$ J. MAdRID (2006): «Ajuar simbólico de la necrópolis tardoantigua del sector oriental de Cartagena», Espacio y Tiempo en la percepción de la Antigüedad Tardía. Homenaje al profesor Antonino González Blanco, in maturitate aetatis ad prudentiam, Antigüedad y Cristianismo 23, pp. 437-463.

\section{ADDENDUM}

Ultimando la redacción de este trabajo, se ha recuperado un ungüentario con este tipo de sello (cf. 4.1.3) durante las labores de excavación de la ladera meridional del Cerro del Molinete, donde se ubicaba el antiguo foro romano de la ciudad. En la actualidad, los autores estudian el contexto de la pieza así como su mismo sello, objeto de un nuevo trabajo. Agradecemos a los directores de la intervención
J. Vizcaíno (2007): «Contra hostes barbaros. Armamento de época bizantina en Carthago Spartaria», Anales de Prehistoria y Arqueología de la Universidad de Murcia 21.

- (2007bis): «Lamellar Armour from Carthago Spartaria (Cartagena, Spain)», Gladius, 27.

- (2008): «Un nuevo tipo de ungüentario bizantino en Cartagena», Antigüedad y Cristianismo 24.

- [en prensa]: «Carthago Spartaria, una ciudad hispana bajo el dominio de los milites Romani», Zona Arqueológica 9. Recópolis: visiones sobre la ciudad en época visigoda.

A.-K. Wassiliou (2004): Die byzantinischen Bleisiegel in Österreich, Wien: Verlag der Österreichischen Akademie der Wissenschaften.

M. Whitrow (1990): «Ruling the Late Roman and Early Byzantine City: A continuous history», Past and Present 129, pp. 3-29.

arqueológica, el profesor de Arqueología de la Universidad de Murcia, Dr. J. M. Noguera Celdrán, y la arqueóloga D. ${ }^{\mathrm{a}} \mathrm{M} .{ }^{\mathrm{a}} \mathrm{J}$. Madrid Balanza, la notificación del hallazgo y las facilidades dadas para su estudio, ahora en curso.

Recibido el 18-04-08. Aceptado el 15-07-08. 